\title{
Análise sobre os impactos do desenvolvimento de lesão renal aguda em pacientes internados em Unidade de Terapia Intensiva
}

Analysis of the impacts of the development of acute kidney injury in patients hospitalized in the Intensive Care Unit

Análisis de los impactos del desarrollo de insuficiencia renal aguda en pacientes hospitalizados en la Unidad de Cuidados Intensivos

Bruno Abilio da Silva Machado

ORCID: https://orcid.org/0000-0003-1759-0206 Centro Universitário Maurício de Nassau, Brasil E-mail: bruno.smachado@ufpe.br

Maria Vitalina Alves de Sousa ORCID: https://orcid.org/0000-0003-4448-2489 Centro Universitário INTA, Brasil E-mail: enf.vitalinaalves@gmail.com

Samuel Lopes dos Santos

ORCID: https://orcid.org/0000-0003-3375-9171 Universidade Federal do Piauí, Brasil

E-mail: samuellopes121314@gmail.com

Winícius de Carvalho Alves

ORCID: https://orcid.org/0000-0003-3118-5696

Centro Universitário Santo Agostinho, Brasil

E-mail: winiciusdecarvalho@hotmail.com

Maciélia Carvalho de Freitas

ORCID: https://orcid.org/0000-0002-1746-6056

Universidade Norde do Paraná, Brasil

E mail: macieliacarvalho@outlook.com

Weberton Dorásio Sobrinho

ORCID: https://orcid.org/0000-0003-0619-7214

Universidade de Rio Verde, Brasil

E-mail: dorasioweberton@gmail.com

Lairton Luís Pinheiro de Melo

ORCID: https://orcid.org/0000-0003-4894-4572

Centro Universitário Uninofapi, Brasil

E-mail: radlairtonmelorad@outlook.com

Luana Pinheiro Lages

ORCID: https://orcid.org/0000-0003-1344-1262

Centro Universitário UniFacid, Brasil

E-mail: luanalages@hotmail.com

Giuliano Araújo Henrique

ORCID: https://orcid.org/0000-0001-9188-5462

Faculdade de Tecnologia e Ciências, Brasil E-mail: giuliano.enf@gmail.com

Aline Oliveira Negreiros

ORCID: https://orcid.org/0000-0003-1803-9475

Centro de Ensino Unificado de Teresina, Brasil E-mail: alinearaujooliver@gmail.com 
Mayara Rayla Silva de Carvalho

ORCID: https://orcid.org/0000-0001-7777-5718 Faculdade Estácio de Teresina, Brasil E-mail: mayaccarw17@gmail.com

Thayna Moreno da Silva

ORCID: https://orcid.org/0000-0002-5905-0235 Centro Universitário Uninta, Brasil

E-mail: thaynamoreno900@gmail.com

Lyanne Isabelle Fonteneles Oliveira ORCID: https://orcid.org/0000-0002-6816-519X

Centro Universitário Santo Agostinho, Brasil

E-mail: lyanneisabelle10@gmail.com

Juliana da Silva Sousa

ORCID: https://orcid.org/0000-0002-5653-9473

Faculdade Christus, Brasil

E-mail: Enfjuh22@gmail.com

Gabriel Oliveira da Silva

ORCID: https://orcid.org/0000-0003-3261-0535

Centro Universitário Uninovafapi, Brasil

E-mail: enf.coisas@gmail.com

Débora Miranda Dias

ORCID: https://orcid.org/0000-0003-1647-7674

Centro Universitário Uninovafapi, Brasil

E-mail: deboram27@hotmail.com

Jéssica Nunes Afonso

ORCID: https://orcid.org/0000-0003-1697-8348

Universidade de Rio Verde, Brasil

E-mail: jessicanunesa94@gmail.com

Nayara Silva Abrantes

ORCID: https://orcid.org/0000-0002-8221-623X

Universidade de Rio Verde, Brasil

E-mail: girlabrantes@gmail.com

Luciana Spindola Monteiro Toussaint

ORCID: https://orcid.org/0000-0001-7691-1570

Fundação Municipal de Saúde, Brasil

E-mail: lucianaspindola09@gmail.com

Felipe de Sousa Moreiras

ORCID: https://orcid.org/0000-0002-8703-1429

Universidade Federal do Piaú, Brasil

E-mail: felipe_moreiras007@ hotmail.com

Érida Zoé Lustosa Furtado

ORCID: https://orcid.org/0000-0002-6162-7558

Universidade Federal do Piauí, Brasil

E-mail: eridazoe@hotmail.com

Carolina Silva Vale

ORCID: https://orcid.org/0000-0001-8269-9705

Hospital Universitário da Universidade Federal do Piauí, Brasil

E-mail: carol.vale.enf@hotmail.com

Erika Lana Soares da Silva

ORCID: https://orcid.org/0000-0001-7125-4284

Centro Universitário Maurício de Nassau, Brasil

E-mail: lannaerika@gmail.com

Laís Christina Araújo Ferreira

ORCID: https://orcid.org/0000-0001-6338-3369

Universidade de Brasília, Brasil

E-mail: laischrisferreira@gmail.com

Aclênia Maria Nascimento Ribeiro

ORCID: https://orcid.org/0000-0002-5582-9663

Universidade Federal do Piauí, Brasil

E-mail: aclennya@hotmail.com

\section{Resumo}

Analisar as evidências científicas publicadas sobre os impactos do desenvolvimento de lesão renal aguda em pacientes internados em Unidade de Terapia Intensiva. O presente estudo trata de uma revisão bibliográfica do método revisão integrativa da literatura, realizado nos meses entre agosto de 2021 a janeiro de 2022. A busca efetuou-se, através da Plataforma da Biblioteca Virtual em Saúde - BVS, utilizando as bases de dados LILACS, BDENF, por meio da SCIELO, aderindo-se através dos descritores e palavras/chaves: "Cuidados de Enfermagem", "Lesão Renal Aguda", "UTI", combinados com o operador booleano "AND". A lesão renal aguda tem representatividade significativa na morbimortalidade dos pacientes na Unidade de Terapia Intensiva (UTI) e está associada a piores desfechos até mesmo 
após a alta hospitalar. Os pacientes críticos são mais suscetíveis a desenvolvê-la principalmente por conta da instabilidade clínica e fatores de riscos prévios, como a idade avançada, sepse, hipovolemia, cirurgias, uso de medicamentos nefrotóxicos, entre outros. O enfermeiro que exerce o papel de cuidado do paciente crítico tem por dever acompanhar, analisar e identificar o desenvolvimento de LRA. A identificação precoce da LRA, ou melhor, a determinação de fatores relacionados ou a definição de características definidoras permitem estabelecer as primeiras diretrizes para a assistência de enfermagem. A equipe de enfermagem que assiste um paciente em cuidados intensivos deve ter acima de tudo comprometimento com a profissão sinalizado pelo cuidado seguro à vida humana, pois mesmo aqueles pacientes assistidos estão predispostos ao desenvolvimento da LRA e agravo do quadro clínico, prognóstico e desfecho.

Palavras-chave: Cuidados de enfermagem; Lesão renal aguda; UTI.

\begin{abstract}
To analyze the published scientific evidence on the impacts of the development of acute kidney injury in patients hospitalized in the Intensive Care Unit. The present study is a literature review of the integrative literature review method, carried out in the months between August 2021 and January 2022. The search was carried out through the Virtual Health Library Platform - VHL, using the LILACS databases , BDENF, through SCIELO, using the descriptors and words/keys: "Nursing Care", "Acute Kidney Injury", "ICU”, combined with the Boolean operator "AND". Acute kidney injury has a significant representation in the morbidity and mortality of patients in the Intensive Care Unit (ICU) and is associated with worse outcomes even after hospital discharge. Critical patients are more susceptible to developing it, mainly due to clinical instability and previous risk factors, such as advanced age, sepsis, hypovolemia, surgeries, use of nephrotoxic drugs, among others. The nurse who plays the role of critical patient care has the duty to monitor, analyze and identify the development of AKI. The early identification of AKI, or rather, the determination of related factors or the definition of defining characteristics allow establishing the first guidelines for nursing care. The nursing team that assists a patient in intensive care must have, above all, a commitment to the profession signaled by the safe care of human life, because even those assisted patients are predisposed to the development of AKI and worsening of the clinical picture, prognosis and outcome.
\end{abstract}

Keywords: Nursing care; Acute kidney injury; ICU.

\title{
Resumen
}

Analizar la evidencia científica publicada sobre los impactos del desarrollo de insuficiencia renal aguda en pacientes hospitalizados en la Unidad de Cuidados Intensivos. El presente estudio es una revisión bibliográfica del método de revisión integradora de literatura, realizada en los meses comprendidos entre agosto de 2021 y enero de 2022 . La búsqueda se realizó a través de la Plataforma Biblioteca Virtual en Salud - BVS, utilizando las bases de datos LILACS, BDENF, a través de SCIELO, utilizando los descriptores y palabras/claves: "Cuidados de Enfermería", "Daño Renal Agudo", "UCI", combinados con el operador booleano "AND". La insuficiencia renal aguda tiene una representación significativa en la morbilidad y mortalidad de los pacientes en la Unidad de Cuidados Intensivos (UCI) y se asocia con peores resultados inclusos después del alta hospitalaria. Los pacientes críticos son más susceptibles a desarrollarla, principalmente por inestabilidad clínica y factores de riesgo previos, como edad avanzada, sepsis, hipovolemia, cirugías, uso de fármacos nefrotóxicos, entre otros. El enfermero que desempeña el papel de cuidado del paciente crítico tiene el deber de monitorear, analizar e identificar el desarrollo de FRA. La identificación precoz del FRA, o mejor dicho, la determinación de factores relacionados o la definición de características definitorias permiten establecer las primeras pautas de atención de enfermería. El equipo de enfermería que asiste a un paciente en cuidados intensivos debe tener, sobre todo, un compromiso con la profesión señalado por el cuidado seguro de la vida humana, pues incluso aquellos pacientes asistidos están predispuestos al desarrollo de DRA y empeoramiento del cuadro clínico, pronóstico y resultado.

Palabras clave: Cuidado de enfermera; Lesión renal aguda; UCI.

\section{Introdução}

A UTI é definida como local com um conjunto de elementos funcionalmente agrupados, destinado ao atendimento de pacientes graves ou de risco que necessitam de assistência e intervenção à saúde ininterrupta, além de equipamentos e recursos especializados. Os cuidados de enfermagem aos pacientes críticos requerem recursos humanos especializados, materiais sofisticados de alta tecnologia com finalidade de oferecer suporte seguro às condições clínicas dos mesmos. Os pacientes com afecções renais necessitam de abordagem integral e sistematizada para avaliação do estado de saúde, em especial no ambiente de UTI, como os distúrbios renais associados à um tempo mais prolongado de hospitalização e custos (Silva et al., 2017).

Os rins desempenham vários papéis importantes para a manutenção da homeostasia corporal, sendo, por exemplo, uma função básica de limpar o plasma sanguíneo de substâncias indesejáveis ao organismo, como as proteínas finais do 
metabolismo, ureia, creatinina, ácido úrico e uratos, através da filtração. Também é responsável pela regulação do equilíbrio hidroeletrolítico, do equilíbrio ácido-básico, pressão arterial, produção de eritropoetina, síntese de vitamina D e secreção de prostaglandinas. $\mathrm{O}$ rim é capaz de realizar a função renal adequada se o rim oposto estiver lesionado ou se apresentar não funcional (Amorin et al., 2017).

A lesão renal aguda (LRA) é uma síndrome clínica reversível com perda rápida da função renal com redução do ritmo de filtração glomerular e/ou oligúria, é determinado por alteração da creatinina sérica e/ou débito urinário. É um problema relevante nas unidades de terapia intensiva (UTIs) e para a saúde pública, por causa do elevado índice de óbito e alto custo do tratamento (Nobre et al., 2021). É uma patologia reversível e uma das complicações mais comuns do ambiente hospitalar, cuja incidência varia de acordo com a gravidade do paciente (Cardoso et al., 2017).

Dessa forma, os principais sinais e sintomas citados da LRA são: oligúria ou anúria, fraqueza, apatia, perda de apetite, náusea, vômitos, respiração de Kussmaul, edema pulmonar, edema periférico, ascite, arritmias cardíacas e coma. O tratamento da LRA, em geral, envolve processos dialíticos e ajuste nutricional e hidroeletrolítico (Aoki et al., 2014).

Segundo Grassi et al. (2017), a lesão renal aguda (LRA) em pacientes internados em unidade de terapia intensiva (UTI) apresenta incidência que varia entre $25 \%$ e $57 \%$ e mortalidade em torno de $60 \%$. A LRA caracteriza-se por perda abrupta da função renal, com redução da taxa de filtração glomerular, gera acúmulo de produtos nitrogenados, distúrbios hidroeletrolíticos e ácido-básico.

De acordo com Carneiro et al. (2017), a lesão renal aguda (LRA) é uma preocupação crescente nas unidades de terapia intensiva. A idade avançada dos pacientes, o aumento da morbidade e a complexidade dos tratamentos oferecidos favorecem o desenvolvimento de LRA. Uma vez que não existe tratamento eficaz para a LRA, todos os esforços visam à prevenção e à detecção precoce, a fim de estabelecer medidas preventivas secundárias para impedir a progressão dessa doença.

O desenvolvimento de complicações durante a internação em uma UTI, tais como infecções, sepse, hemorragias, cirurgias e necessidade de diálise, pode fazer com que o nível de severidade do paciente e da LRA seja maior. Em pacientes hospitalizados, a LRA é considerada uma das complicações mais importantes, sendo que sua incidência varia de acordo com as condições clínicas dos pacientes, ocorrendo em maior quantidade em UTIs (20 a 40\%) e em menor quantidade em unidades intermediárias. Fatores diversos podem contribuir para taxa elevada de mortalidade em LRA, particularmente a não identificação de fatores de risco, diagnóstico tardio da doença ou desconhecimento de fatores associados à mortalidade (Luft et al., 2016).

Assim, objetivando a diminuição da mortalidade, bem como das complicações ocasionadas pela LRA no ambiente hospitalar é que a enfermagem como integrante da equipe multidisciplinar, deve participar ativamente do plano de cuidados oferecidos ao paciente diagnosticado com LRA. Os mesmos declaram ainda, que as ações devem estar pautadas no conhecimento técnico e científico, e que a assistência de enfermagem deve ser realizada de modo ágil e preciso, a fim de contribuir para melhor prognóstico ao paciente. Dessa forma, o enfermeiro após a realização do processo de anamnese e exame físico, terá dados que poderão classificar se o paciente está incluso em algum grupo de risco para o desenvolvimento da patologia, e caso já esteja acometido pela LRA, esse profissional poderá indicar os diagnósticos de enfermagem relacionados a essa patologia, e a partir do planejamento das ações, poderá executar as ações de forma qualificada, contribuindo para prevenir as complicações da LRA e ainda impedir a progressão da doença (Silva et al., 2021).

O cuidado de enfermagem a pacientes com LRA torna-se desafiador na prática clínica por exigir do profissional um raciocínio clínico e pensamento crítico na tomada de decisão. Para tanto, este deve ter abordagem sistematizada, de forma integral, permitindo que o enfermeiro melhor avalie o estado de saúde dos pacientes, de forma a estabelecer intervenções adequadas e de forma individualizada, principalmente para aqueles internados em UTI, devido à incidência de distúrbios renais associados ao tempo de hospitalização mais prolongado. Assim, no que diz respeito ao gerenciamento do cuidado de 
enfermagem ao portador de LRA, o Processo de Enfermagem (PE) torna-se uma ferramenta de imprescindível uso, que por meio da Sistematização da Assistência de Enfermagem (SAE), permite ao enfermeiro gerenciar e desenvolver uma assistência mais dinâmica, organizada, adequada e segura (Corrêa et al., 2020).

As principais intervenções de enfermagem para o paciente com LRA são direcionadas ao controle e a monitorização hídrica, da hipervolemia e dos eletrólitos. Pode-se, também, encontrar intervenções visando o controle da eliminação urinária e o controle acidobásico do sangue, o controle e proteção contra infecções, supervisão da pele e cuidados com lesões, precauções contra sangramentos, assim como a monitorização nutricional e respiratória do paciente (Corrêa et al., 2020).

O desenvolvimento da lesão renal aguda em pacientes hospitalizados prolonga o tempo de internação, eleva os custos do tratamento e a taxa de mortalidade. Essa realidade retrata a premente necessidade de implementação de medidas preventivas, para preservar a função renal e minimizar complicações, além de reduzir a necessidade de terapia renal substitutiva. As medidas preventivas devem se iniciar a partir da avaliação dos indivíduos em risco e podem ser farmacológicas ou não, ou ainda norteadas por ações que minimizam a exposição ou a suscetibilidade ao desenvolvimento de lesão renal aguda (Santos, \& Magro, 2015).

Diante da temática em discussão, surge como questão norteadora do estudo: "Quais os impactos do desenvolvimento de lesão renal aguda em pacientes internados em Unidade de Terapia Intensiva"? Assim, o objetivo do presente estudo é analisar as evidências científicas publicadas sobre os impactos do desenvolvimento de lesão renal aguda em pacientes internados em Unidade de Terapia Intensiva.

A realização do presente estudo relacionado à temática, é essencial para a construção coletiva do conhecimento, pois, o estudo possibilita a sociedade acadêmica e cientifica a ampliar o conhecimento sobre os impactos do desenvolvimento de lesão renal aguda em pacientes internados em Unidade de Terapia Intensiva. Desse modo, o estudo trará contribuições pertinentes, na medida em que acrescentará as evidências científicas discussões relevantes a respeito dessa temática tão importante.

\section{Metodologia}

O presente estudo trata de uma revisão bibliográfica do método revisão integrativa da literatura, realizado nos meses entre agosto de 2021 a janeiro de 2022. A revisão configura-se, portanto, como um tipo de revisão da literatura que reúne achados de estudos desenvolvidos mediante diferentes metodologias, permitindo aos revisores sintetizar resultados sem ferir a filiação epistemológica dos estudos empíricos incluídos. Para que esse processo concretize-se de maneira lógica, isenta de desatinos epistemológicos, a revisão requer que os revisores procedam à análise e à síntese dos dados primários de forma sistemática e rigorosa (Soares et al., 2014).

A revisão da literatura serve para reconhecer a unidade e a diversidade interpretativa existente no eixo temático em que se insere o problema em estudo, para ampliar, ramificar a análise interpretativa, bem como para compor as abstrações e sínteses que qualquer pesquisa requer colaborando para a coerência nas argumentações do pesquisador. Nesse sentido, a revisão integrativa é um método que tem como finalidade reunir e sintetizar resultados de pesquisas sobre um delimitado tema ou questão, de maneira sistemática e ordenada e abrangente, contribuindo para o aprofundamento do conhecimento do tema investigado (Ferenhof \& Fernandes, 2016). 
Figura 1. Fluxograma fases distintas da revisão integrativa.

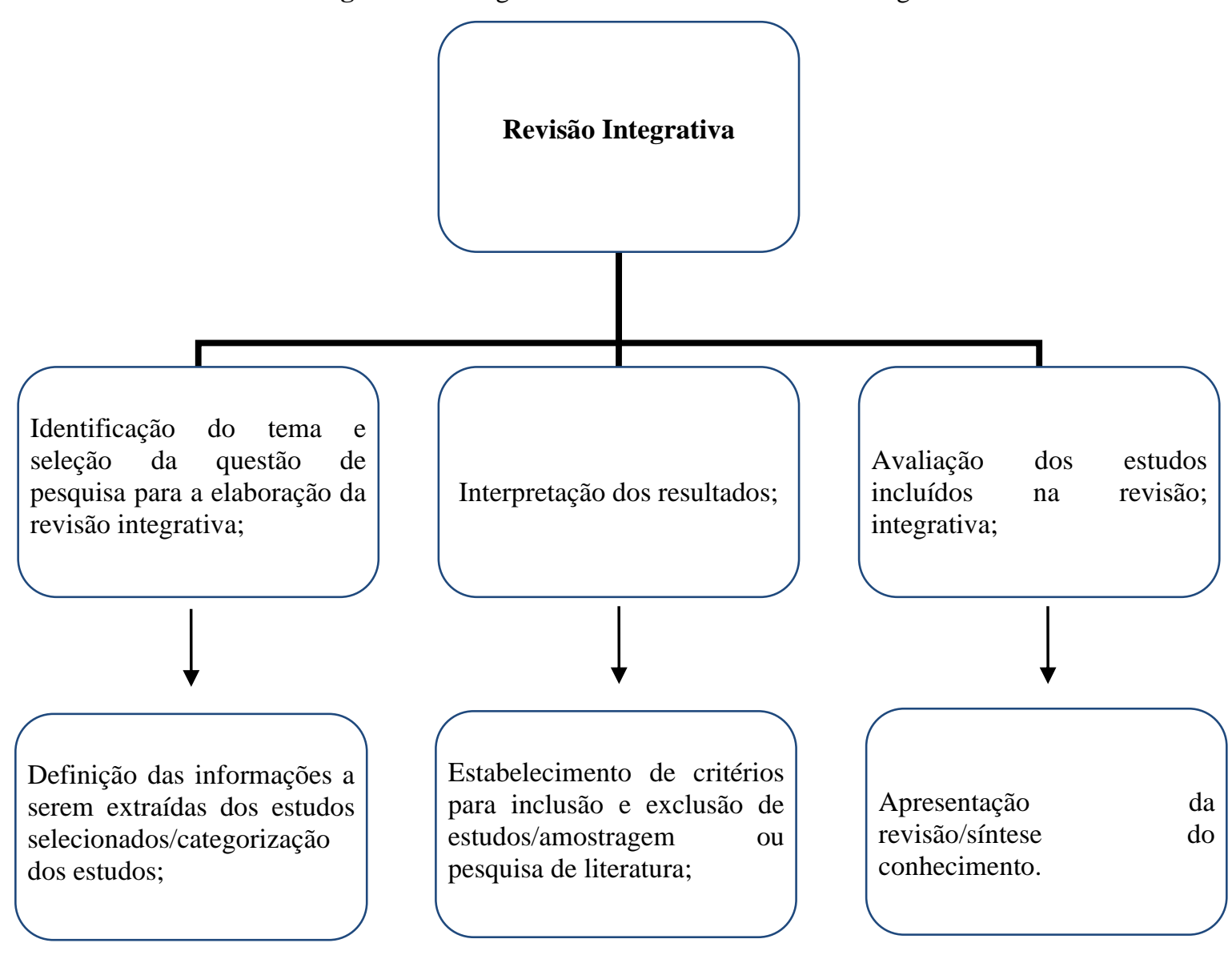

Fonte: Mendes et al. (2008).

A revisão integrativa é um tipo de pesquisa que fornece informações mais amplas de maneira sistemática, ordenada e abrangente, sobre um assunto ou tema, com a finalidade de sintetizar resultados obtidos em pesquisa sobre temas ou questões. A definição das informações a serem extraídas dos estudos selecionados por categorização; avaliação dos estudos incluídos; interpretação dos resultados; e apresentação da revisão/síntese do conhecimento (Ercole et al., 2015).

Estudo elaborado com abordagem qualitativa tornando-se importante a interpretação por parte do pesquisador com suas opiniões sobre o fenômeno em estudo. Neste tipo de pesquisa destacam-se algumas características como: a pesquisa qualitativa, em geral, ocorre no ambiente natural com coleta direta de dados e o pesquisador é o principal instrumento; os dados coletados são preferencialmente descritivos; a preocupação do processo é predominante em relação à do produto; a análise de dados e informações tende a seguir um processo indutivo (Pereira et al., 2018).

A pesquisa qualitativa envolve uma abordagem interpretativa do mundo, o que significa que seus pesquisadores estudam as coisas em seus cenários naturais, tentando entender os fenômenos em termos dos significados que as pessoas a eles conferem. A pesquisa qualitativa atribui importância fundamental aos depoimentos dos atores sociais envolvidos, aos discursos e aos significados transmitidos por eles. Nesse sentido, esse tipo de pesquisa preza pela descrição detalhada dos fenômenos e dos elementos que o envolvem (Augusto et al., 2014).

De acordo com Souza et al. (2010), a ser realizada nas seguintes etapas: 1- Elaboração da pergunta norteadora; 2Busca nas bases de dados e amostragem; 3- Coleta de dados, 4- Análise crítica.

Para responder à questão norteadora do estudo: "Quais os impactos do desenvolvimento de lesão renal aguda em pacientes internados em Unidade de Terapia Intensiva"? Aplicou-se os descritores/palavras-chaves: "Cuidados de Enfermagem", "Lesão Renal Aguda", "UTI”. 
A busca efetuou-se, através da Plataforma da Biblioteca Virtual em Saúde - BVS, utilizando as bases de dados Literatura Latino-Americana e do Caribe em Ciências da Saúde (LILACS), Base de Dados de Enfermagem (BDENF), por meio da - Scientific Electronic Library Online (SCIELO). Aderindo-se através dos descritores/palavras chaves: "Cuidados de Enfermagem", "Lesão Renal Aguda", "UTI”, combinados com o operador booleano “AND”.

Os critérios de inclusão estabelecidos foram: artigos originais disponibilizados na íntegra, completos, que abrangessem a temática e na forma online, publicados nos idiomas português, inglês e espanhol, publicações que respondiam a questão norteadora do estudo. Os critérios de exclusão estabelecidos na seleção foram: artigos incompletos, artigos duplicados, teses, dissertações, monografias, manuais, e publicações que não estavam de acordo com a questão norteadora do estudo. No início da pesquisa obteve-se 10500 publicações, após a aplicação dos critérios de inclusão e exclusão totalizou-se parcialmente 910 artigos, depois de uma leitura mais precisa aderiu-se um total final de 24 publicações de acordo para serem trabalhadas na elaboração do referido estudo.

O fluxograma representado abaixo, caracteriza a estratégia de coleta de dados utilizada pelos autores, no sentido de detalhar as principais evidencias encontradas no estudo. 
Figura 2. Fluxograma Estratégia de Busca - Bases de Dados, Teresina-PI, Brasil, 2022.

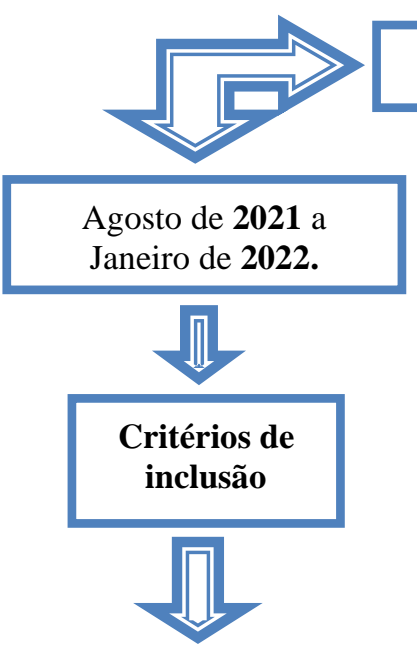

Artigos originais disponibilizados na íntegra, completos, que abrangessem a temática e na forma online, publicados nos idioma português, inglês e espanhol, publicações que respondiam a questão norteadora do estudo. Estratégia de Busca Revisão Integrativa

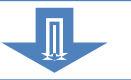

\section{Critérios de exclusão}

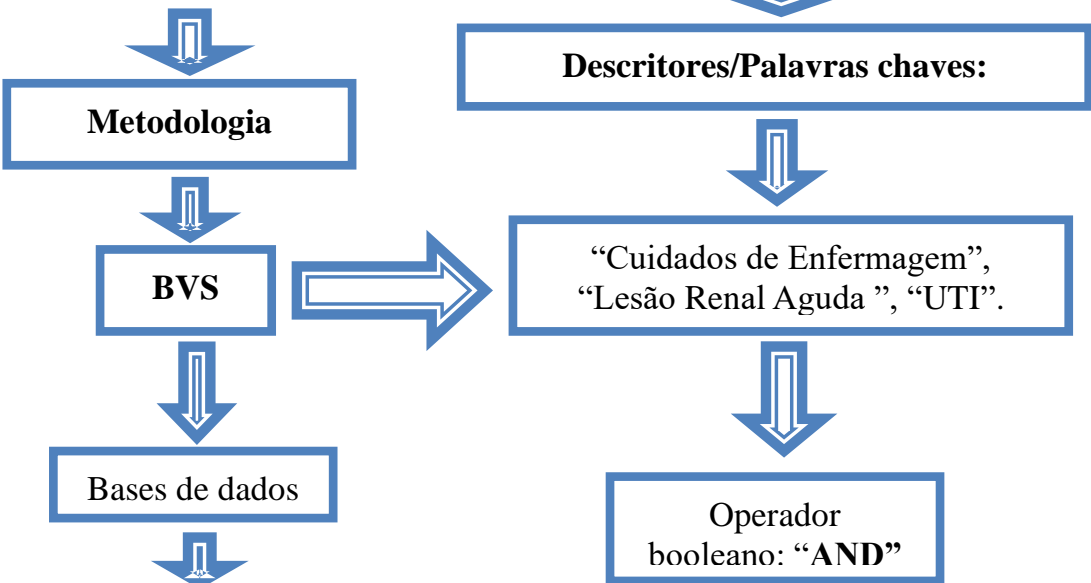

Artigos incompletos, artigos duplicados, teses, dissertações, monografias, manuais, e publicações que não estavam de acordo com a questão norteadora do estudo

.
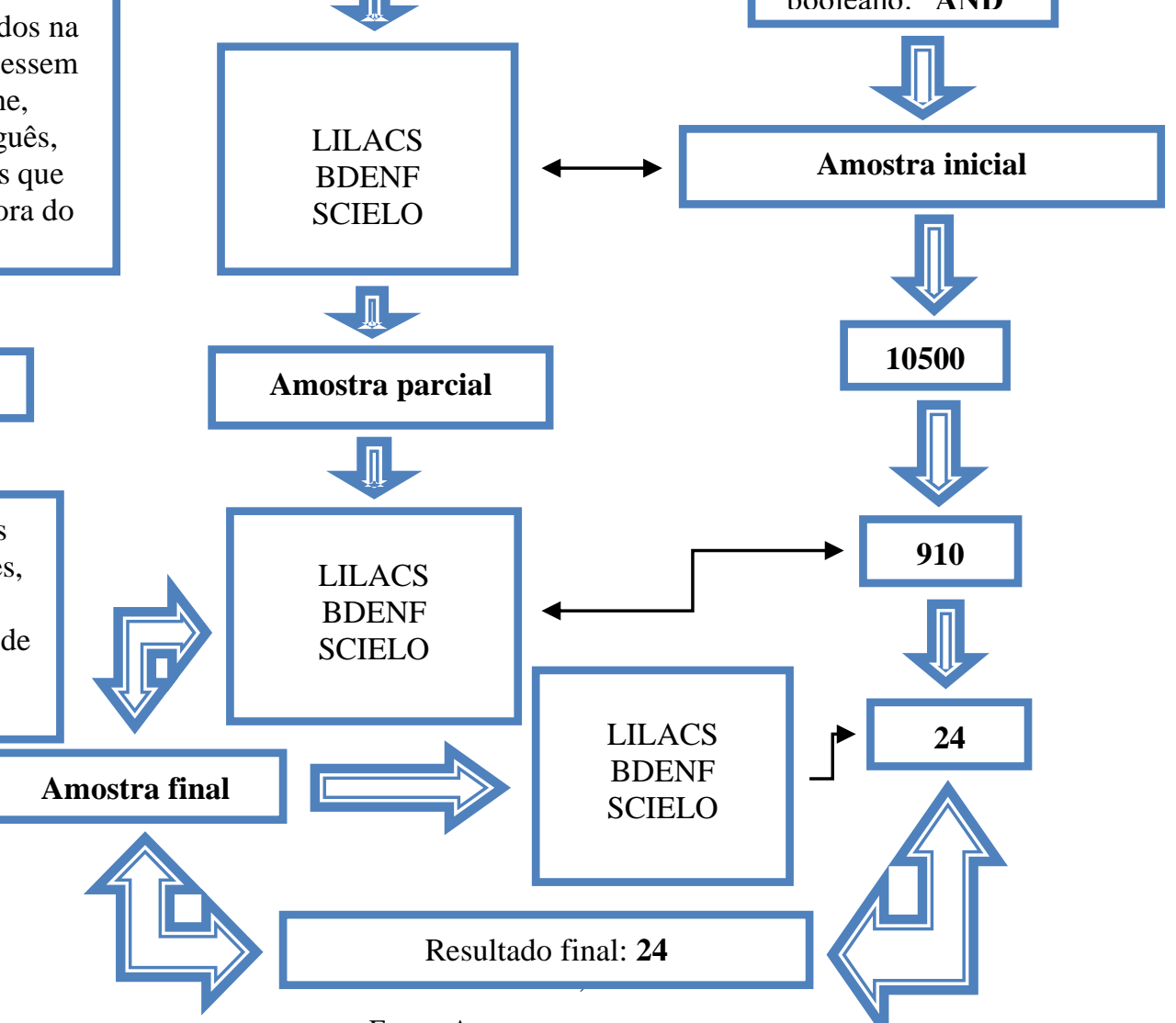

No Fluxograma 2, estão expostos a estratégia de busca, bases de dados, período de realização do estudo, critérios de inclusão e exclusão, amostra inicial, parcial e final, de acordo com a quantidade de artigos que irão compor os resultados do estudo.

O presente estudo assegura os aspectos éticos, garantindo a autoria dos artigos pesquisados, utilizando para as citações e referências dos autores as normas APA. Os preceitos éticos estabelecidos no que se refere a zelar pela legitimidade das informações, privacidade e sigilo das informações, quando necessárias, tornando os resultados desta pesquisa públicos. Os pesquisadores buscaram a legitimidade e fidelidade nas citações dos autores seja nas citações diretas ou parafraseadas no estudo. 


\section{Resultados e Discussão}

Diante dos resultados obtidos no estudo por meio da estratégia de busca, os autores delinearam variáveis para melhor descrever as evidências encontradas na pesquisa. O quadro a seguir caracteriza os artigos com base nas variáveis propostas: número do artigo, base de dados, periódico, autor e ano de publicação, tipo de estudo, título, objetivo, resultados em evidências e conclusões importantes.

Quadro 1. Caracterização dos artigos selecionados para o estudo.

\begin{tabular}{|c|c|c|c|c|c|c|c|}
\hline $\mathbf{N}$ & $\begin{array}{l}\text { Base de } \\
\text { Dados }\end{array}$ & Periódico & $\begin{array}{l}\text { Autor e } \\
\text { Ano }\end{array}$ & $\begin{array}{l}\text { Tipo de } \\
\text { Estudo }\end{array}$ & Título & Objetivo & $\begin{array}{c}\text { Resultados em evidências e conclusões } \\
\text { importantes }\end{array}$ \\
\hline 1 & SCIELO & $\begin{array}{c}\text { Research, } \\
\text { Society and } \\
\text { Developme } \\
\text { nt. }\end{array}$ & $\begin{array}{l}\text { Nobre } e t \\
\text { al., } 2021 .\end{array}$ & $\begin{array}{c}\text { Estudo } \\
\text { descritivo } \\
\text { qualitativo. }\end{array}$ & $\begin{array}{l}\text { Lesão renal aguda: } \\
\text { assistência de } \\
\text { enfermagem du - } \\
\text { rante a sessão de } \\
\text { hemodiálise em } \\
\text { Unidade de } \\
\text { Terapia Intensiva. }\end{array}$ & $\begin{array}{l}\text { Analisar e descrever } \\
\text { as intervenções de } \\
\text { enfermagem frente a } \\
\text { paciente com lesão } \\
\text { renal aguda nas } \\
\text { principais interco- } \\
\text { rrências no decurso da } \\
\text { sessão de hemodiálise } \\
\text { em unidade de terapia } \\
\text { intensiva. }\end{array}$ & $\begin{array}{l}\text { Percebeu-se que a LRA é uma patologia } \\
\text { multifatorial e que pode ser antecipada } \\
\text { por alguns achados. Independente de } \\
\text { como a LRA seja classificada, o paciente } \\
\text { apresentará desequilíbrio ácido-básico e } \\
\text { hidroeletrolítico, impactando } \\
\text { negativamente na evolução do quadro } \\
\text { clínico e bem estar do mesmo, o que leva } \\
\text { a uma instabilidade hemodinâmica, } \\
\text { podendo até mesmo ir a óbito pela } \\
\text { gravidade da doença. Nesta perspectiva, } \\
\text { torna-se indispensável o papel do } \\
\text { enfermeiro quando se discute o processo } \\
\text { saúde doença, pois é um profissional } \\
\text { capacitado, habilitado e que possui } \\
\text { conhecimento técnico-cientifico e } \\
\text { raciocínio crítico reflexivo nas tomadas de } \\
\text { decisões. }\end{array}$ \\
\hline 2 & LILACS & $\begin{array}{l}\text { Cogitare } \\
\text { Enferm. }\end{array}$ & $\begin{array}{l}\text { Cardoso, } \\
\text { Carneiro, } \\
\& \text { Magro, } \\
2017 .\end{array}$ & $\begin{array}{c}\text { Estudo } \\
\text { observacional } \\
\text { prospectivo e } \\
\text { quantitativo. }\end{array}$ & $\begin{array}{l}\text { Recuperação de } \\
\text { pacientes com } \\
\text { lesão renal aguda } \\
\text { dialítica e não } \\
\text { dialítica. }\end{array}$ & $\begin{array}{c}\text { Identificar a } \\
\text { recuperação da função } \\
\text { renal de pacientes } \\
\text { com lesão renal aguda } \\
\text { dialítica e não } \\
\text { dialítica. }\end{array}$ & $\begin{array}{l}\text { A LRA é complicação frequente no } \\
\text { cenário da UTI, geralmente relacionada a } \\
\text { outras patologias e medicamentos. } \\
\text { Observou-se o quantitativo expressivo de } \\
\text { pacientes, de ambos os grupos (dialítico e } \\
\text { não dialítico) que evoluíram com lesão ou } \\
\text { falência renal de acordo com a } \\
\text { classificação AKIN. }\end{array}$ \\
\hline 3 & LILACS & Revisa. & $\begin{array}{l}\text { Pereira, } \\
\text { \& Silva, } \\
2010 .\end{array}$ & $\begin{array}{l}\text { Estudo } \\
\text { prospectivo. }\end{array}$ & $\begin{array}{l}\text { Lesão Renal } \\
\text { Aguda por } \\
\text { Síndrome da Lise } \\
\text { Tumoral em } \\
\text { Unidade de } \\
\text { Terapia Intensiva- } \\
\text { Conhecimento do } \\
\text { Enfermeiro. }\end{array}$ & $\begin{array}{c}\text { Analisar sobre a lesão } \\
\text { renal aguda causada } \\
\text { pela síndrome da lise } \\
\text { tumoral no paciente } \\
\text { internado em unidade } \\
\text { de terapia intensiva, } \\
\text { bem como o } \\
\text { conhecimento do } \\
\text { enfermeiro sobre tal } \\
\text { patologia. }\end{array}$ & $\begin{array}{l}\text { Dentre os fatores de risco para } \\
\text { desenvolver LRA, destacam-se as doenças } \\
\text { clínicas preexistentes, intervenções } \\
\text { terapêuticas, além da susceptibilidade } \\
\text { individual que podem repercutir na função } \\
\text { renal. Também há relação com o processo } \\
\text { de envelhecimento, atrelado às doenças } \\
\text { crônico-degenerativas e alterações renais } \\
\text { morfofuncionais. O diagnóstico precoce } \\
\text { da LRA está diretamente relacionado ao } \\
\text { melhor prognóstico de pacientes clínicos } \\
\text { críticos, e dentre as estratégias } \\
\text { comumente utilizadas, tem-se a } \\
\text { mensuração de marcadores biológicos, a } \\
\text { partir da análise de dados laboratoriais, } \\
\text { que sinalizam alterações agudas. }\end{array}$ \\
\hline 4 & BDENF & $\begin{array}{l}\text { Rev } \\
\text { Enferm } \\
\text { UFPE On } \\
\text { lin. }\end{array}$ & $\begin{array}{r}\text { Silva et } \\
\text { al., } 2017 .\end{array}$ & $\begin{array}{l}\text { Estudo } \\
\text { qualitativo. }\end{array}$ & $\begin{array}{l}\text { Distúrbios renais } \\
\text { em Unidade de } \\
\text { Terapia Intensiva. }\end{array}$ & $\begin{array}{c}\text { Identificar os } \\
\text { principais distúrbios } \\
\text { renais em pacientes } \\
\text { internados em } \\
\text { Unidade de Terapia } \\
\text { Intensiva. } \\
\end{array}$ & $\begin{array}{l}\text { Dentre os principais distúrbios renais } \\
\text { encontrados em pacientes internados na } \\
\text { UTI, relacionavam-se à IRA, como } \\
\text { sepses, choque séptico, ITU, doenças } \\
\text { respiratórias e cardiovasculares. }\end{array}$ \\
\hline 5 & LILACS & $\begin{array}{l}\text { Acta Paul } \\
\text { Enferm. }\end{array}$ & $\begin{array}{l}\text { Grassi, } \\
\text { Dell'Acq } \\
\text { ua, } \\
\text { Jensen, } \\
\text { Fontes, \& } \\
\text { Guimarãe } \\
\text { s, } 2017 .\end{array}$ & $\begin{array}{l}\text { Estudo } \\
\text { transversal. }\end{array}$ & $\begin{array}{l}\text { Diagnósticos, re- } \\
\text { sultados e } \\
\text { intervenções de } \\
\text { enfermagem em } \\
\text { pacientes com } \\
\text { lesão renal aguda. }\end{array}$ & $\begin{array}{c}\text { Identificar prevalência } \\
\text { de diagnósticos (DE), } \\
\text { resultados (RE) e } \\
\text { intervenções de } \\
\text { enfermagem (IE) em } \\
\text { pacientes com lesão } \\
\text { renal aguda (LRA) } \\
\text { internados em unidade } \\
\text { de terapia intensiva } \\
\text { (UTI). }\end{array}$ & $\begin{array}{l}\text { O perfil dos pacientes com LRA em } \\
\text { tratamento dialítico em UTI é do sexo } \\
\text { masculino }(60 \%) \text {, com idade superior a } 60 \\
\text { anos }(33 \%) \text {, com diagnóstico médico } \\
\text { primário relacionado à patologia do trato } \\
\text { gastrointestinal }(36 \%) \text { e sepse esta } \\
\text { presente em } 37 \% \text { dos casos. O tipo de } \\
\text { lesão renal mais frequente foi a pré-renal } \\
\text { em } 54 \% \text { dos pacientes, sendo necessária a } \\
\text { terapia de substituição renal no primeiro } \\
\text { dia de admissão na UTI }(46 \%) \text {. }\end{array}$ \\
\hline
\end{tabular}




\begin{tabular}{|c|c|c|c|c|c|c|c|}
\hline 6 & LILACS & $\begin{array}{l}\text { Acta Paul } \\
\text { Enferm. }\end{array}$ & $\begin{array}{l}\text { Santos, \& } \\
\text { Magro, } \\
2014 .\end{array}$ & $\begin{array}{l}\text { Estudo de } \\
\text { coorte, } \\
\text { prospectivo, } \\
\text { quantitativo. }\end{array}$ & $\begin{array}{l}\text { Ventilação mecâ - } \\
\text { nica e a lesão } \\
\text { renal aguda em } \\
\text { pacientes na } \\
\text { unidade de terapia } \\
\text { intensiva. }\end{array}$ & $\begin{array}{c}\text { Verificar o impacto } \\
\text { do emprego da } \\
\text { ventilação mecânica } \\
\text { em pacientes } \\
\text { internados na Unidade } \\
\text { de Terapia Intensiva e } \\
\text { a ocorrência de lesão } \\
\text { renal aguda. }\end{array}$ & $\begin{array}{l}\text { Verifica-se que o emprego da ventilação } \\
\text { mecânica invasiva com pressão positiva } \\
\text { no final da expiração em pacientes graves } \\
\text { pode determinar prejuízos à função renal } \\
\text { dos pacientes internados em unidade de } \\
\text { terapia intensiva. }\end{array}$ \\
\hline 7 & BDENF & $\begin{array}{l}\text { REME - } \\
\text { Rev Min } \\
\text { Enferm. }\end{array}$ & $\begin{array}{l}\text { Carneiro, } \\
\text { Hermann } \\
\text {, Souza, } \\
\text { \& Magro, } \\
2020 .\end{array}$ & $\begin{array}{l}\text { Estudo } \\
\text { observacional, } \\
\text { prospectivo e } \\
\text { quantitativo. }\end{array}$ & $\begin{array}{l}\text { Identificação e } \\
\text { recuperação da } \\
\text { função renal em } \\
\text { pacientes não } \\
\text { dialíticos no } \\
\text { cenário de terapia } \\
\text { intensiva. }\end{array}$ & $\begin{array}{l}\text { Determinar o grau de } \\
\text { comprometimento da } \\
\text { função renal de } \\
\text { pacientes que } \\
\text { evoluíram com LRA } \\
\text { não dialítica e } \\
\text { identificar a } \\
\text { frequência de } \\
\text { recuperação da função } \\
\text { renal na unidade de } \\
\text { terapia intensiva } \\
\text { (UTI). }\end{array}$ & $\begin{array}{l}\text { O enfermeiro atuante na UTI adulto deve } \\
\text { manter-se capacitado e atualizado quanto } \\
\text { às evidências cientificas sobre sepse, } \\
\text { buscando também treinar e capacitar à } \\
\text { equipe, visto que esses profissionais têm } \\
\text { papel muito importante na propagação de } \\
\text { conhecimento e educação permanente, } \\
\text { pois ele planeja e coordena as ações de } \\
\text { enfermagem apoiado no conhecimento } \\
\text { técnico científico. }\end{array}$ \\
\hline 8 & SCIELO & $\begin{array}{c}\text { Rev. } \\
\text { Latino-Am. } \\
\text { Enfermage } \\
\text { m. }\end{array}$ & $\begin{array}{l}\text { Aoki, } \\
\text { Fram, } \\
\text { Taminato } \\
\text {, Batista, } \\
\text { Belasco, } \\
\quad \& \\
\text { Barbosa, } \\
2014\end{array}$ & $\begin{array}{l}\text { Estudo de } \\
\text { coorte } \\
\text { longitudinal. }\end{array}$ & $\begin{array}{l}\text { Lesão renal aguda } \\
\text { após exame } \\
\text { contrastado em } \\
\text { idosos. }\end{array}$ & $\begin{array}{l}\text { Avaliar a função renal } \\
\text { em idosos submetidos } \\
\text { a tomografia } \\
\text { computadorizada com } \\
\text { contraste e identificar } \\
\text { o uso de medidas } \\
\text { preventivas da lesão } \\
\text { renal aguda, nos } \\
\text { períodos antes e após } \\
\text { o exame. }\end{array}$ & $\begin{array}{l}\text { Muitos idosos realizam exame com a } \\
\text { utilização de contraste, porém, o } \\
\text { protocolo implementado na instituição } \\
\text { sobre as possíveis medidas preventivas de } \\
\text { alteração da função renal não está sendo } \\
\text { cumprido. Apesar de os idosos estarem } \\
\text { internados, não se encontraram registros } \\
\text { claros sobre as medidas preventivas que } \\
\text { deveriam ser utilizadas antes e após a } \\
\text { realização dos exames contrastados, nessa } \\
\text { faixa etária. }\end{array}$ \\
\hline 9 & SCIELO & $\begin{array}{l}\text { Cogitare } \\
\text { Enferm. }\end{array}$ & $\begin{array}{l}\text { Luft, } \\
\text { Boes, } \\
\text { Lazzari, } \\
\text { Nascime } \\
\text { nto, } \\
\text { Busana, } \\
\quad \& \\
\text { Canever, } \\
2016 .\end{array}$ & $\begin{array}{l}\text { Estudo } \\
\text { quantitativo, } \\
\text { documental, } \\
\text { retrospectivo. }\end{array}$ & $\begin{array}{l}\text { Lesão renal aguda } \\
\text { em unidade de } \\
\text { tratamento inten- } \\
\text { sivo: característi - } \\
\text { cas clínicas e } \\
\text { desfechos. }\end{array}$ & $\begin{array}{l}\text { Caracterizar o perfil } \\
\text { clínico-demográfico e } \\
\text { o desfecho de } \\
\text { pacientes com } \\
\text { insuficiência renal, } \\
\text { submetidos à terapia } \\
\text { dialítica em uma } \\
\text { unidade de terapia } \\
\text { intensiva } \\
\text { adulto. }\end{array}$ & $\begin{array}{l}\text { Portanto, os principais fatores } \\
\text { relacionados à infecção de corrente } \\
\text { sanguínea por uso de CVC estão } \\
\text { associados a falhas em protocolos de } \\
\text { segurança do paciente. Contudo, os } \\
\text { profissionais de enfermagem, com } \\
\text { destaque para atuação do enfermeiro, são } \\
\text { responsáveis por evitar/minimizar essas } \\
\text { infecções no contexto das UTIs adulto, } \\
\text { mediante intervenções respaldadas em } \\
\text { recomendações dos órgãos competentes, } \\
\text { como a ANVISA. }\end{array}$ \\
\hline $\begin{array}{l}1 \\
0\end{array}$ & SCIELO & $\begin{array}{l}\text { Rev Bras } \\
\text { Enferm. }\end{array}$ & $\begin{array}{l}\text { Coelho, } \\
\text { Watanab } \\
\quad \text { e, } \\
\text { Fonseca, } \\
\text { Padilha, } \\
\quad \& \\
\text { VattimoI } \\
2017 . \\
\end{array}$ & $\begin{array}{c}\text { Estudo } \\
\text { quantitativo. }\end{array}$ & $\begin{array}{l}\text { Nursing Activities } \\
\text { Score e a lesão } \\
\text { renal aguda. }\end{array}$ & $\begin{array}{l}\text { Avaliar a carga de } \\
\text { trabalho de } \\
\text { enfermagem em } \\
\text { pacientes de terapia } \\
\text { intensiva com lesão } \\
\text { renal aguda (LRA).. }\end{array}$ & $\begin{array}{l}\text { O NAS dos pacientes com LRA foi maior } \\
\text { quando comparado aos indivíduos que } \\
\text { não desenvolveram LRA. O NAS se elevo } \\
\text { com o agravamento da LRA pelos } \\
\text { critérios do KDIGO, confirmando maior } \\
\text { necessidade de cuidados de enfermagem } \\
\text { entre esses pacientes. }\end{array}$ \\
\hline $\begin{array}{l}1 \\
1\end{array}$ & SCIELO & $\begin{array}{c}\text { Research, } \\
\text { Society and } \\
\text { Developme } \\
\text { nt. }\end{array}$ & $\begin{array}{l}\text { Silva, } \\
\text { Souza, } \\
\text { Sousa, } \\
\text { Watanab } \\
\quad \text { e, } \\
\text { Fonseca, } \\
\text { Vattimo, } \\
2020 .\end{array}$ & $\begin{array}{l}\text { Estudo de } \\
\text { coorte } \\
\text { prospectivo. }\end{array}$ & $\begin{array}{l}\text { Identificação de } \\
\text { lesão renal aguda } \\
\text { em unidade de } \\
\text { terapia intensiva: } \\
\text { parâmetros para } \\
\text { avaliação clínica } \\
\text { de enfermagem. }\end{array}$ & $\begin{array}{l}\text { Identificar a } \\
\text { prevalência de lesão } \\
\text { renal aguda em } \\
\text { pacientes de Unidade } \\
\text { de Terapia Intensiva }\end{array}$ & $\begin{array}{l}\text { A prevalência de LRA identificada pelo } \\
\text { AKIN foi superior quando comparada a } \\
\text { avaliação isolada da elevação da } \\
\text { creatinina sérica. Os parâmetros de } \\
\text { avalição adotados no AKIN são } \\
\text { usualmente utilizados pela enfermagem } \\
\text { em UTI. }\end{array}$ \\
\hline $\begin{array}{l}1 \\
2\end{array}$ & SCIELO & $\begin{array}{c}\text { Research, } \\
\text { Society and } \\
\text { Developme } \\
\text { nt. }\end{array}$ & $\begin{array}{l}\text { Silva, } \\
\text { Lemos, } \\
\text { Santos, \& } \\
\text { Dourado, } \\
2021 .\end{array}$ & $\begin{array}{l}\text { Estudo } \\
\text { descritivo, } \\
\text { qualitativo do } \\
\text { tipo relato de } \\
\text { experiência. }\end{array}$ & $\begin{array}{l}\text { Assistência de } \\
\text { enfermagem ao } \\
\text { paciente com } \\
\text { lesão renal aguda: } \\
\text { relato de } \\
\text { experiência. }\end{array}$ & $\begin{array}{l}\text { Identificar como deve } \\
\text { ocorrer a assistência } \\
\text { de enfermagem frente } \\
\text { ao paciente com LRA } \\
\text { no ambiente intra- } \\
\text { hospitalar. }\end{array}$ & $\begin{array}{l}\text { Tendo em vista os prejuízos ocasionados } \\
\text { pela LRA, e sabendo-se que essa se } \\
\text { enquadra como um problema de saúde } \\
\text { pública. Ressalta-se, que o processo de } \\
\text { educação permanente, além de transmitir } \\
\text { informações clínicas sobre a LRA, } \\
\text { auxiliará os enfermeiros a manusear de } \\
\text { forma correta essa ferramenta, garantindo } \\
\text { cuidado integral a cada paciente, } \\
\text { contribuindo para diminuição da } \\
\text { mortalidade por essa patologia. }\end{array}$ \\
\hline
\end{tabular}




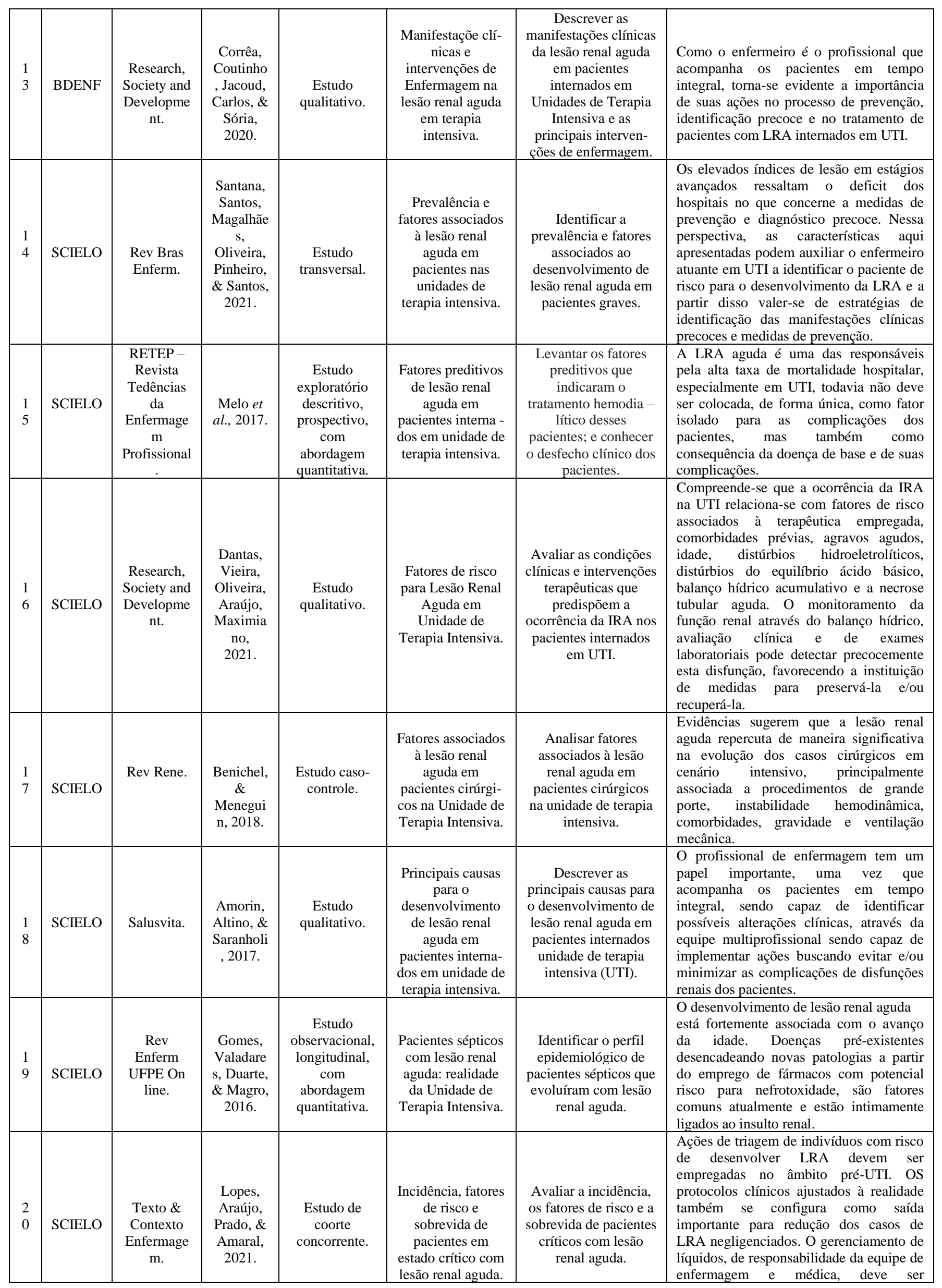




\begin{tabular}{|c|c|c|c|c|c|c|c|}
\hline & & & & & & & rigorosamente realizado. \\
\hline $\begin{array}{l}2 \\
1\end{array}$ & SCIELO & $\begin{array}{l}\text { Rev Bras } \\
\text { Enferm. }\end{array}$ & $\begin{array}{c}\text { Vasco, } \\
\text { Watanab } \\
\text { e, } \\
\text { Fonseca, } \\
\& \\
\text { Vattimo, } \\
2018 .\end{array}$ & $\begin{array}{c}\text { Estudo } \\
\text { quantitativo } \\
\text { experimental. }\end{array}$ & $\begin{array}{l}\text { Lesão renal aguda } \\
\text { induzida pela } \\
\text { sepse: efeito de } \\
\text { proteção renal dos } \\
\text { antioxidantes. }\end{array}$ & $\begin{array}{c}\text { Avaliar a ação } \\
\text { antioxidantereno pro- } \\
\text { tetora da N- } \\
\text { acetilcisteína e da } \\
\text { diosmina-hesperidina } \\
\text { no modelo } \\
\text { experimental da LRA } \\
\text { induzida pela sepse. }\end{array}$ & $\begin{array}{l}\text { A busca por terapias que minimizem os } \\
\text { danos renais na presença de sepse tem } \\
\text { sido frequente nas unidades de terapia } \\
\text { intensiva. Cabe ao enfermeiro, enquanto } \\
\text { membro da equipe multidisciplinar, cuidar } \\
\text { dos pacientes nas diferentes situações, de } \\
\text { forma integrada e contínua, dentro dos } \\
\text { preceitos éticos e bioéticos da profissão, } \\
\text { buscando conhecer tratamentos inova- } \\
\text { dores que promovam melhor assistência } \\
\text { de enfermagem aos pacientes com sepse. }\end{array}$ \\
\hline $\begin{array}{l}2 \\
2\end{array}$ & SCIELO & $\begin{array}{l}\text { Rev Soc } \\
\text { Bras Clin } \\
\text { Med. }\end{array}$ & $\begin{array}{l}\text { Pereira et } \\
\text { al., } 2016 .\end{array}$ & $\begin{array}{l}\text { Estudo clínico, } \\
\text { prospectivo, } \\
\text { observacional. }\end{array}$ & $\begin{array}{l}\text { Lesão renal aguda } \\
\text { no pós-operatório } \\
\text { de cirurgias não } \\
\text { cardíacas em } \\
\text { pacientes com } \\
\text { recuperação na } \\
\text { Unidade de } \\
\text { Terapia Intensiva. }\end{array}$ & $\begin{array}{l}\text { Caracterizar os fatores } \\
\text { de risco para lesão } \\
\text { renal aguda em } \\
\text { pacientes submetidos } \\
\text { a cirurgias não } \\
\text { cardíacas na unidade } \\
\text { de terapia intensiva e } \\
\text { sua influência na } \\
\text { evolução clínica no } \\
\text { pós-operatório. }\end{array}$ & $\begin{array}{l}\text { A presença da lesão renal aguda complica } \\
\text { a evolução clínica de pacientes no pós- } \\
\text { operatório, mesmo em cirurgias não } \\
\text { cardíacas. Os pacientes idosos submetidos } \\
\text { à cirurgia eletiva e classificados no risco } \\
\text { cirúrgico ASA } 3 \text { apresentaram maior risco } \\
\text { para desenvolvimento de lesão renal } \\
\text { aguda no pós-operatório desse tipo de } \\
\text { cirurgia. Os idosos que evoluíram } \\
\text { dialíticos tiveram maior mortalidade no } \\
\text { pós-operatório. A presença de algum grau } \\
\text { de disfunção renal crônica no pré- } \\
\text { operatório é o fator de maior risco do } \\
\text { desenvolvimento de piora da função. }\end{array}$ \\
\hline $\begin{array}{l}2 \\
3\end{array}$ & SCIELO & $\begin{array}{c}\text { Revista } \\
\text { Eletrônica } \\
\text { Acervo } \\
\text { Saúde. }\end{array}$ & $\begin{array}{c}\text { Silva } e t \\
\text { al., } 2021 .\end{array}$ & $\begin{array}{l}\text { Estudo } \\
\text { qualitativo. }\end{array}$ & $\begin{array}{l}\text { Manejo da lesão } \\
\text { renal aguda. }\end{array}$ & $\begin{array}{c}\text { Descrever fatores de } \\
\text { risco, etiofisiopatolo- } \\
\text { gia e manejo da Lesão } \\
\text { Renal Aguda (LRA) } \\
\text { em pacientes } \\
\text { internados em } \\
\text { Unidade de Terapia } \\
\text { Intensiva (UTI). }\end{array}$ & $\begin{array}{l}\text { A LRA é uma importante causa de } \\
\text { mortalidade em pacientes em tratamento } \\
\text { intensivo. Ela afeta o organismo não } \\
\text { apenas a nível renal, mas de forma } \\
\text { sistêmica, causando prejuízos a vários } \\
\text { outros órgãos. Por apresentar difícil } \\
\text { manejo e pela alta taxa de mortalidade } \\
\text { associada, torna-se imprescindível a } \\
\text { identificação de pacientes com maior } \\
\text { risco de desenvolver LRA, visando } \\
\text { estabelecer medidas preventivas. Além } \\
\text { disso, é essencial diagnosticar a LRA } \\
\text { precocemente, visando fornecer uma } \\
\text { terapia de manutenção e evitar uma futura } \\
\text { intervenção mais invasiva. }\end{array}$ \\
\hline $\begin{array}{l}2 \\
4\end{array}$ & SCIELO & $\begin{array}{l}\text { New } \\
\text { Trends in } \\
\text { Qualitative } \\
\text { Research. }\end{array}$ & $\begin{array}{l}\text { Santos, \& } \\
\text { Noivas, } \\
2021 .\end{array}$ & $\begin{array}{l}\text { Estudo } \\
\text { qualitativo. }\end{array}$ & $\begin{array}{l}\text { Mapeamento de } \\
\text { Intervenções de } \\
\text { Enfermagem na } \\
\text { Lesão Renal } \\
\text { Aguda: Scoping } \\
\text { Review. }\end{array}$ & $\begin{array}{c}\text { Mapear as } \\
\text { intervenções de } \\
\text { enfermagem à pessoa } \\
\text { com lesão renal aguda } \\
\text { em unidade de } \\
\text { cuidados intensivos. }\end{array}$ & $\begin{array}{l}\text { A prevenção é a melhor estratégia de gerir } \\
\text { a LRA e o enfermeiro tem de focar as } \\
\text { suas intervenções na identificação dos } \\
\text { fatores de risco e nas causas da LRA. Para } \\
\text { o diagnóstico da LRA, existem } 3 \\
\text { classificações para detectar a LRA. O } \\
\text { enfermeiro é um elemento crucial na } \\
\text { equipa multidisciplinar para classificar a } \\
\text { LRA de acordo com a sua gravidade, para } \\
\text { atuar/intervir o mais precocemente } \\
\text { possível no seu tratamento, com vista às } \\
\text { necessidades do doente, promovendo a } \\
\text { sua recuperação. }\end{array}$ \\
\hline
\end{tabular}

Fonte: Autores (2022).

No Quadro 1, tem-se a apresentação dos artigos selecionados para o estudo conforme número do artigo, base de dados, periódico, autor e ano de publicação, tipo de estudo, título, objetivo, resultados em evidências e conclusões importantes, com a finalidade de facilitar o desenvolvimento da discussão. A partir do estudo dos artigos estabeleceram-se discussões relevantes para observações das produções científicas relacionadas à pesquisa.

No Gráfico 1, a seguir, estão expostos os periódicos e a quantidade de artigos encontrados na seleção da amostra final dos artigos que são trabalhados na elaboração do referido estudo. 
Gráfico 1. Distribuição dos artigos conforme periódico e quantidade de artigos.

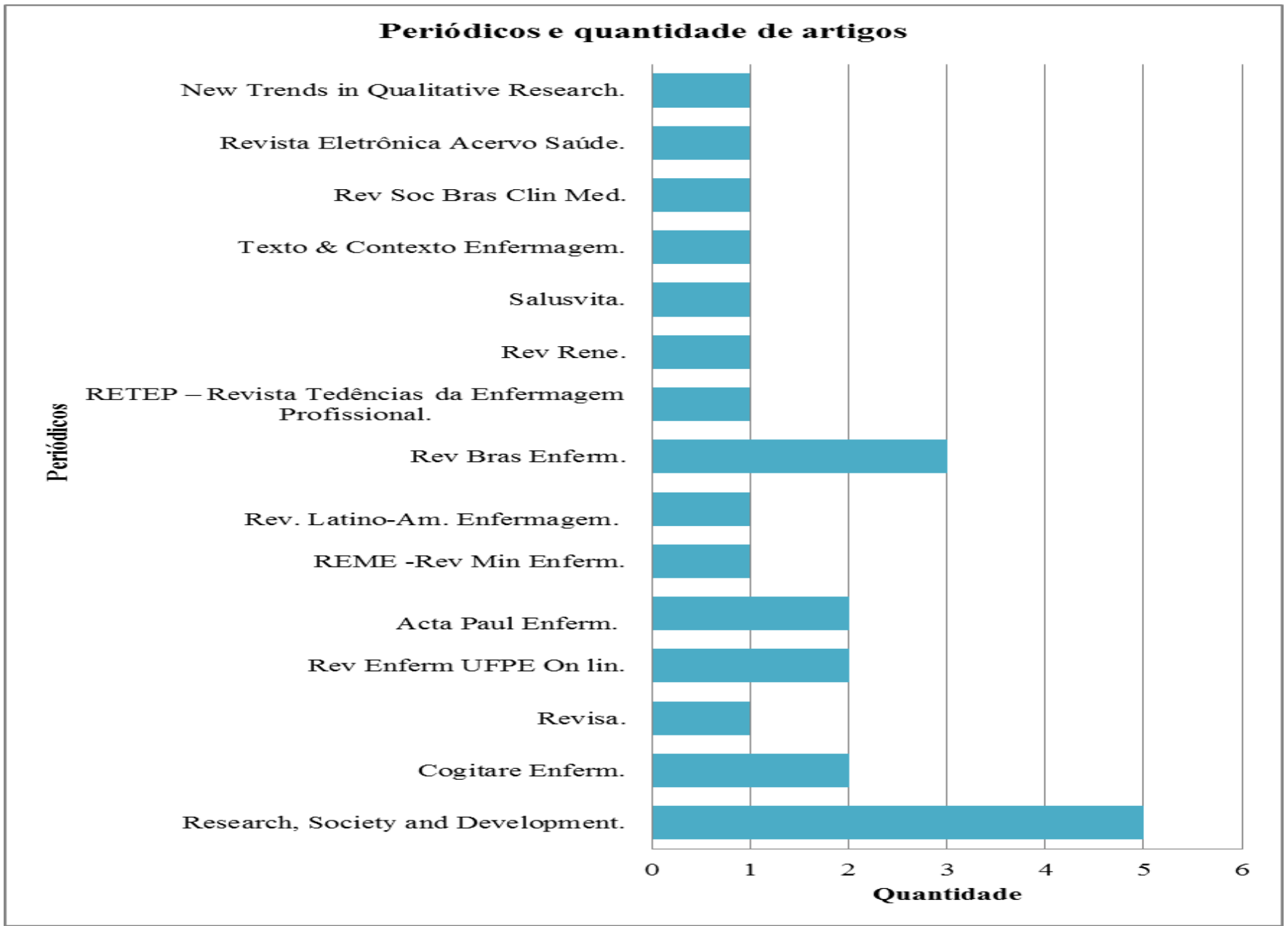

Fonte: Autores (2022).

Segundo o gráfico ilustrado acima, pode-se observar os periódicos e a quantidade de artigos que foram publicados de acordo com a amostra final do referido estudo. Dessa forma, verifica-se que na revista New Trends in Qualitative Research ocorreu (1) publicação, Rev Eletrônica Acervo Saúde (1), Rev Soc Bras Clin Med (1), Texto \& Contexto Enfermagem (1), Salusvita (1), Rev Rene (1), RETEP - Revista Tendências da Enfermagem Profissional (1), Rev Bras Enferm (3), Rev Latino Am Enfermagem (1), REME - Rev Min Enferm (1) Acta Paul Enferm (2), Rev Enferm UFPE Online (2), Revisa (1), Cogitare Enferm (2), Research, Society and Development (5). Assim, totalizando 24 artigos para serem trabalhados na elaboração do presente estudo.

De acordo, com o gráfico ilustrado acima, pode-se observar os periódicos e a porcentagem de artigos que foram publicados de acordo com a amostra final do referente estudo. Dessa forma, verifica-se que. Assim, totalizando 24 artigos para serem trabalhados na construção do presente estudo. 
Gráfico 2. Distribuição dos artigos conforme periódico e porcentagens.

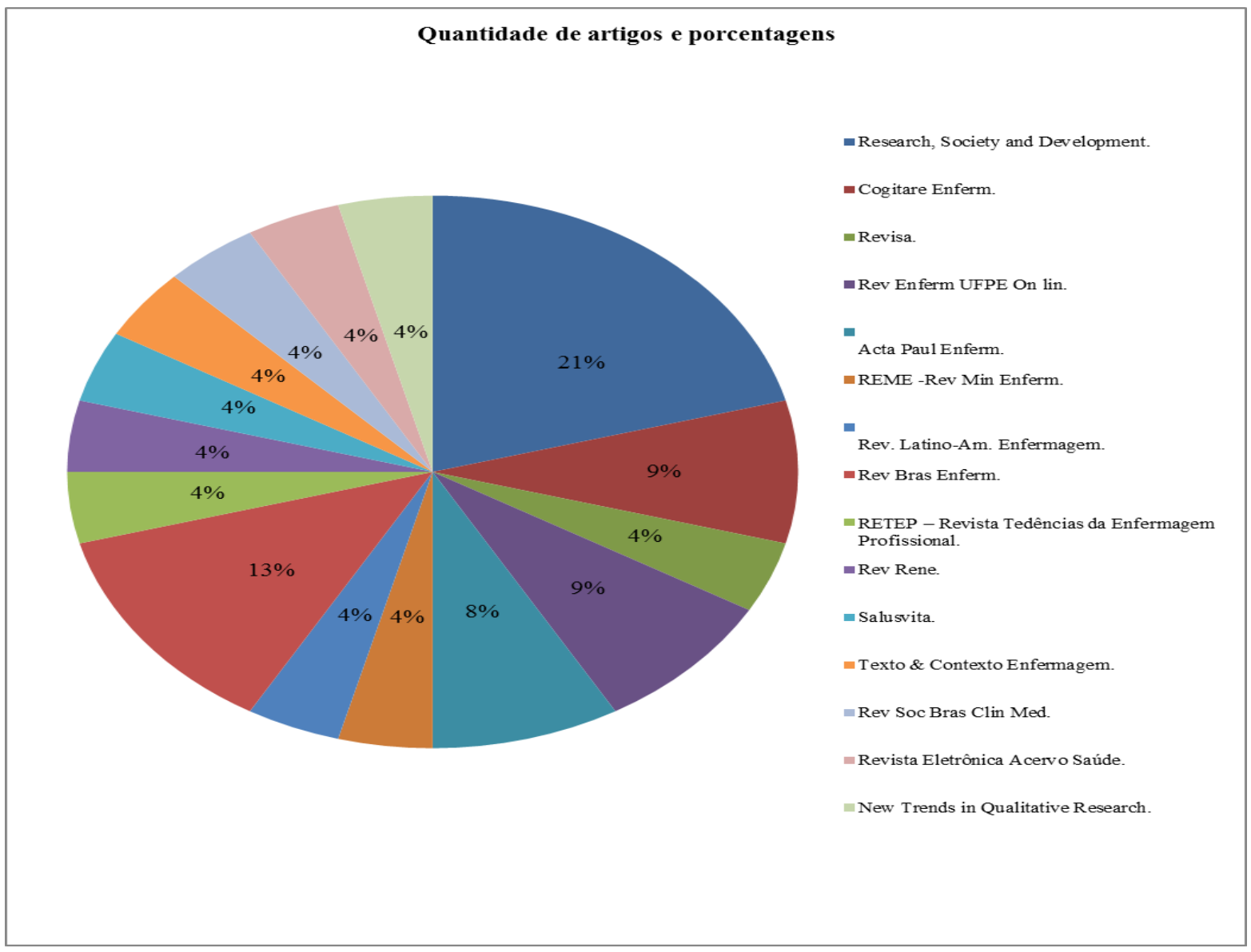

Fonte: Autores (2022).

Ao analisar o gráfico representado acima, percebe-se os periódicos e a porcentagem de artigos publicados, indentificase- que que na revista New Trends in Qualitative Research ocorreu (4\%) publicação, Rev Eletrônica Acervo Saúde (4\%), Rev Soc Bras Clin Med (4\%), Texto \& Contexto Enfermagem (4\%), Salusvita (4\%), Rev Rene (4\%), RETEP - Revista Tendências da Enfermagem Profissional (4\%), Rev Bras Enferm (13\%), Rev Latino Am Enfermagem (4\%), REME - Rev Min Enferm (4\%) Acta Paul Enferm (8\%), Rev Enferm UFPE Online (9\%), Revisa (4\%), Cogitare Enferm (9\%), Research, Society and Development (21\%). Totalizando $100 \%$ dos artigos publicados. 
Gráfico 3. Distribuição dos artigos conforme os anos de publicação e quantidade.

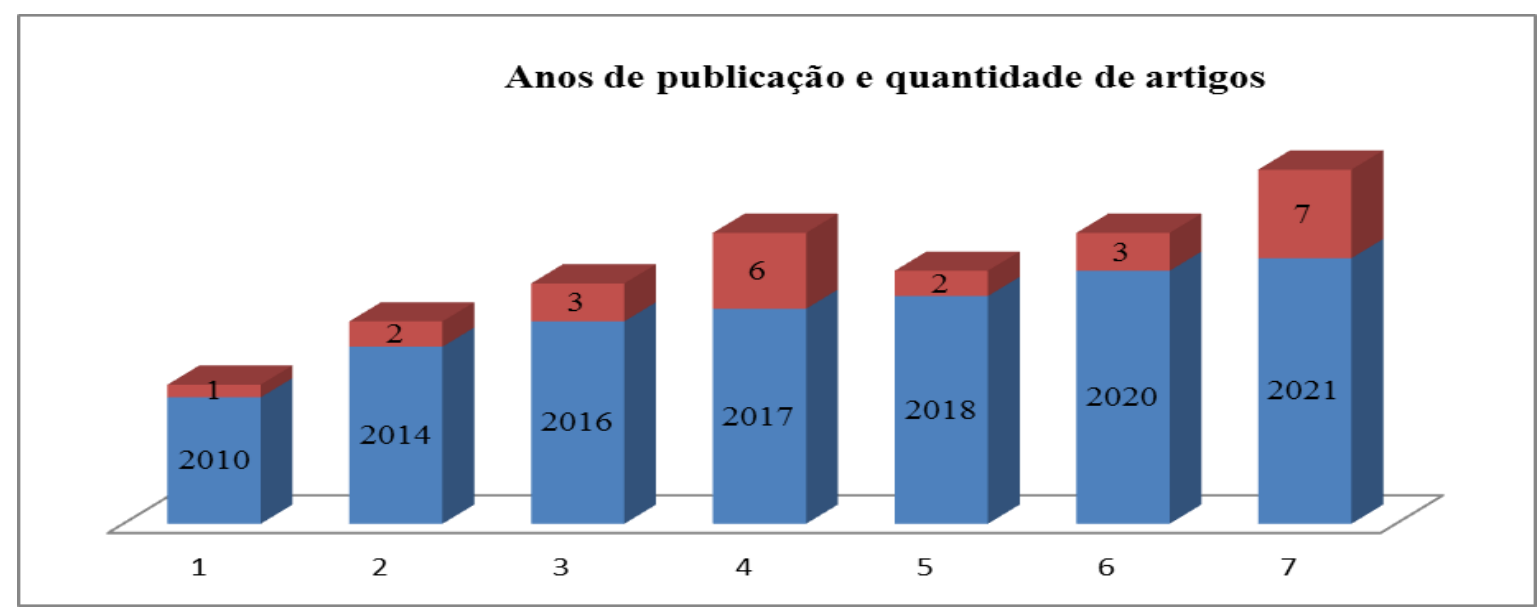

Fonte: Autores (2022).

Ao analisar o gráfico representado acima, observa-se os anos de publicação e a quantidade de artigos publicados, nota-se que no ano de 2010 ocorreu (1) publicação, 2014 (2), 2016 (3), 2017 (6), 2018 (2), 2020 (3), 2021 (7) .Assim, totalizando 24 artigos publicados e selecionados para serem utilizados na elaboração do presente estudo.

Gráfico 4. Distribuição dos anos de publicação e porcetagem.

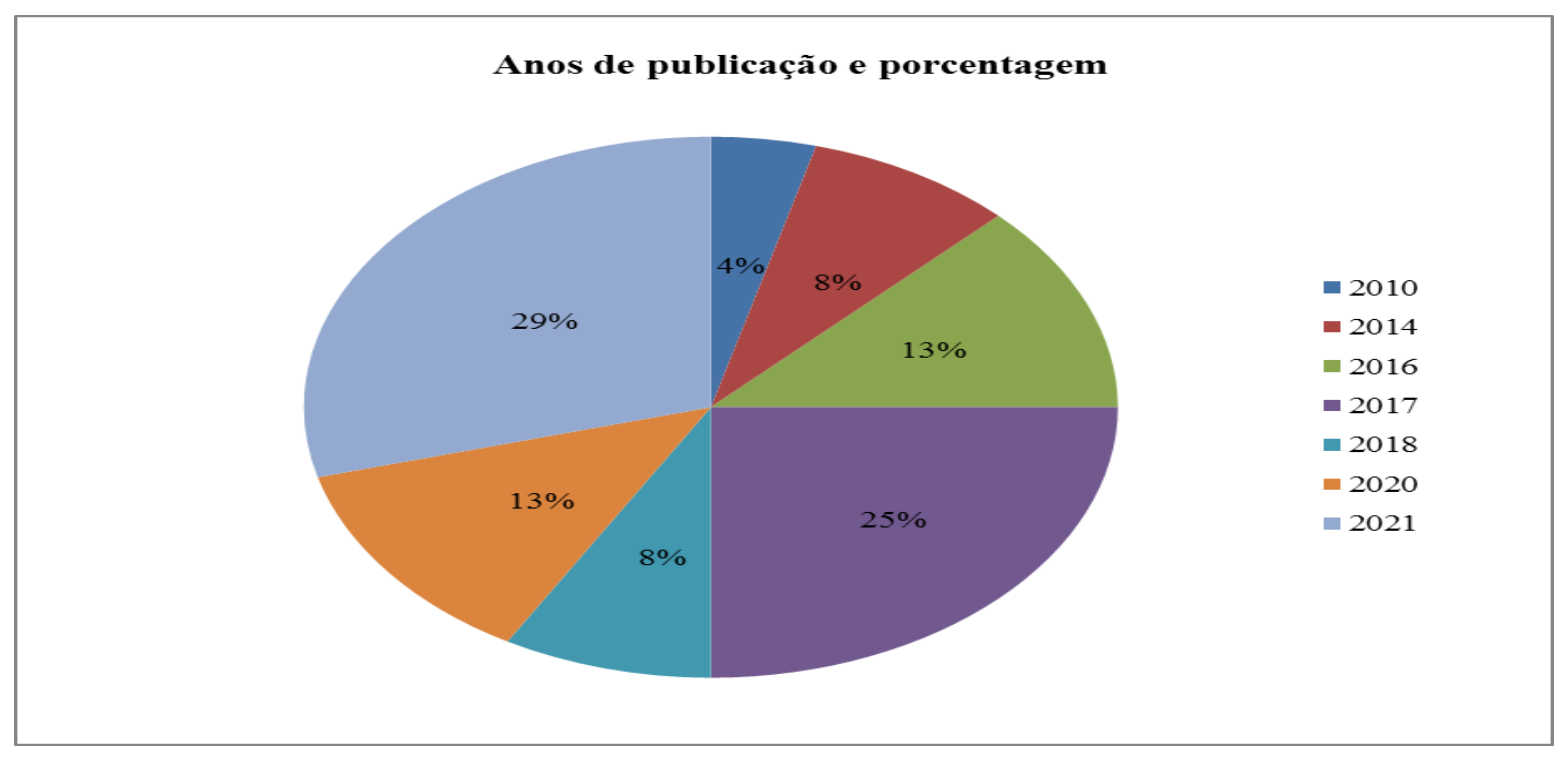

Fonte: Autores (2022).

Ao verificar o gráfico acima, percebe-se os anos de publicação e porcentagem dos artigos publicados de acordo com cada ano, identifica-se que no ano de 2010 ocorreu (4\%) publicação, 2014 (8\%), 2016 (13\%), 2017 (25\%), 2018 (\%), 2020 (13\%), 2021 (29\%). Totalizando 100\% das publicações, escolhidas para compor a construção do referido estudo. 
Research, Society and Development, v. 11, n. 3, e25811326257, 2022

(CC BY 4.0) | ISSN 2525-3409 | DOI: http://dx.doi.org/10.33448/rsd-v11i3.26257

Gráfico 5. Distribuição dos artigos conforme os tipos de estudo e quantidade.

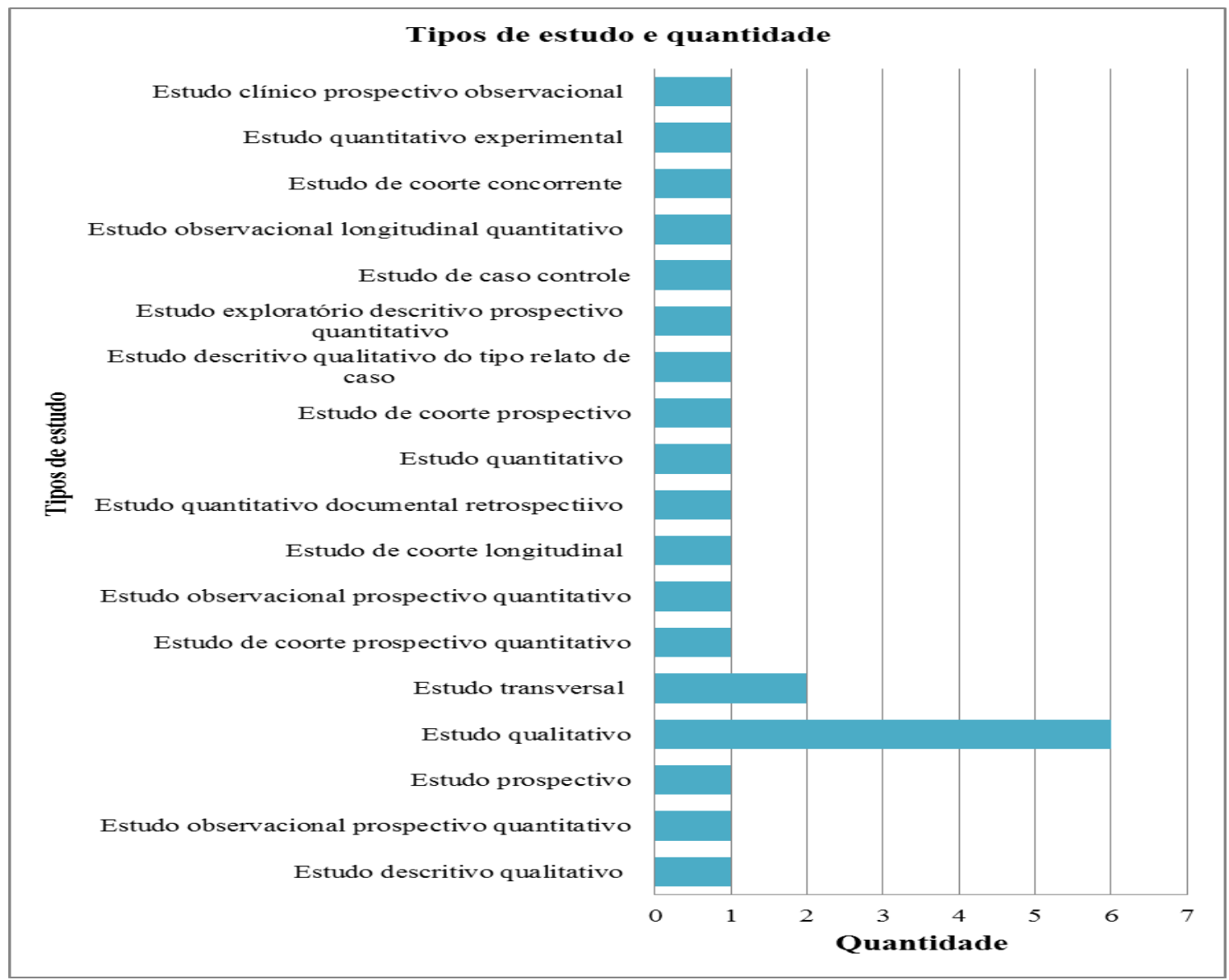

Fonte: Autores (2022).

Ao analisar o gráfico representado acima, identificam-se os tipos de estudo e a quantidade de artigos publicados. Nota-se que, evidenciou-se um total de: Estudo clínico prospectivo observacional (1), estudo quantitativo experimental (1), estudo de coorte concorrente (1), estudo observacional longitudinal quantitativo (1), estudo caso - controle (1), estudo exploratório descritivo prospectivo quantitativo (1), estudo descritivo do tipo relato de experiência (1), estudo de coorte prospectivo (1), estudo quantitativo (1), estudo quantitativo documental retrospectivo (1), estudo de coorte longitudinal (1), estudo observacional prospectivo quantitativo (1), estudo de coorte prospectivo quantitativo (1), estudo transversal (2), estudo qualitativo (6), estudo prospectivo (1), estudo observacional prospectivo quantitativo (1), estudo descritivo qualitativo (1). Totalizando 24 estudos selecionados na amostra final para construção do presente estudo. 
Gráfico 6. Distribuição dos tipos de estudos e porcentagem.

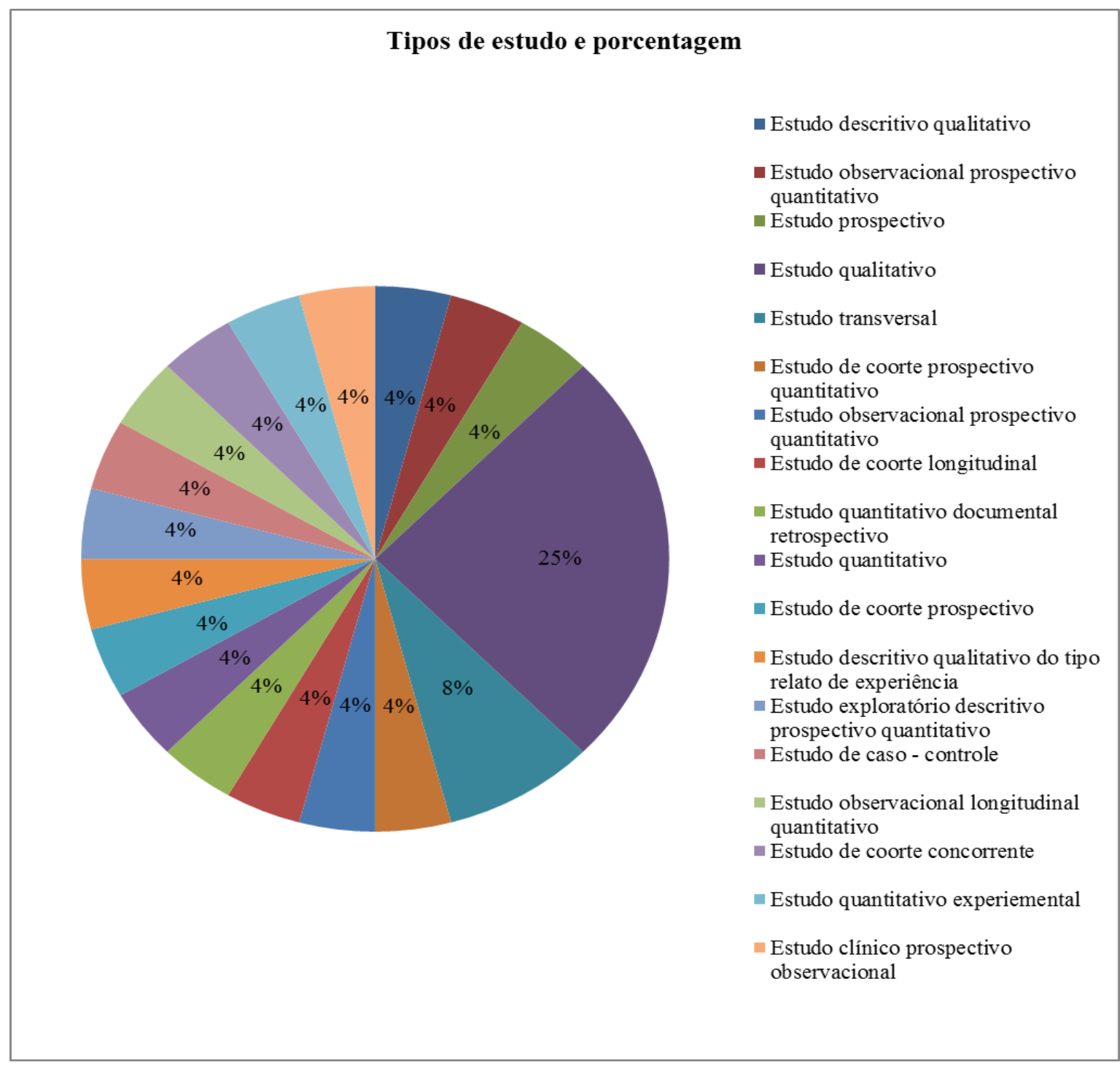

Fonte: Autores (2022).

Ao analisar o gráfico ilustrado acima, nota-se os tipos de estudo e a porcentagem de artigos publicados. Assim evidencia-se que: Estudo clínico prospectivo observacional (4\%), estudo quantitativo experimental (4\%), estudo de coorte concorrente (4\%), estudo observacional longitudinal quantitativo (4\%), estudo caso - controle (4\%), estudo exploratório descritivo prospectivo quantitativo (4\%), estudo descritivo do tipo relato de experiência (4\%), estudo de coorte prospectivo (4\%), estudo quantitativo (4\%), estudo quantitativo documental retrospectivo (4\%), estudo de coorte longitudinal (4\%), estudo observacional prospectivo quantitativo (4\%), estudo de coorte prospectivo quantitativo (4\%), estudo transversal (8\%), estudo qualitativo (25\%), estudo prospectivo (4\%), estudo observacional prospectivo quantitativo (4\%), estudo descritivo qualitativo $(4 \%)$. 
Gráfico 7. Distribuição dos artigos de acordo com as bases de dados e a quantidade de artigos.

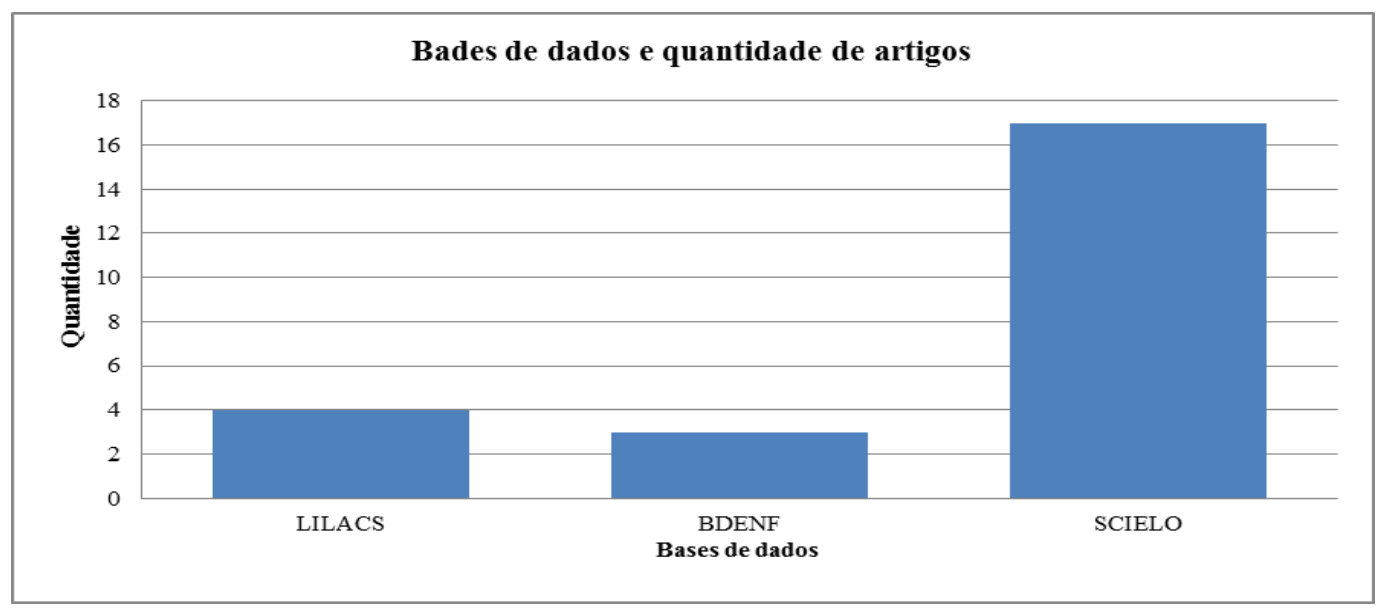

Fonte: Autores (2022).

Segundo o gráfico representado acima é possível identificar as bases de dados e a quantidade de artigo publicados em cada uma. Nota - se que na Literatura Latino-Americana e do Caribe em Ciências da Saúde (LILACS) ocorreu (4) publicações, Base de Dados de Enfermagem (BDENF), (3) e - Scientific Electronic Library Online (SCIELO) (17). Sendo que foram adotados os critérios metodológicos na elaboração do referido estudo.

Gráfico 8. Distribuição dos artigos de acordo com as bases de dados e a porcentagem de artigos.

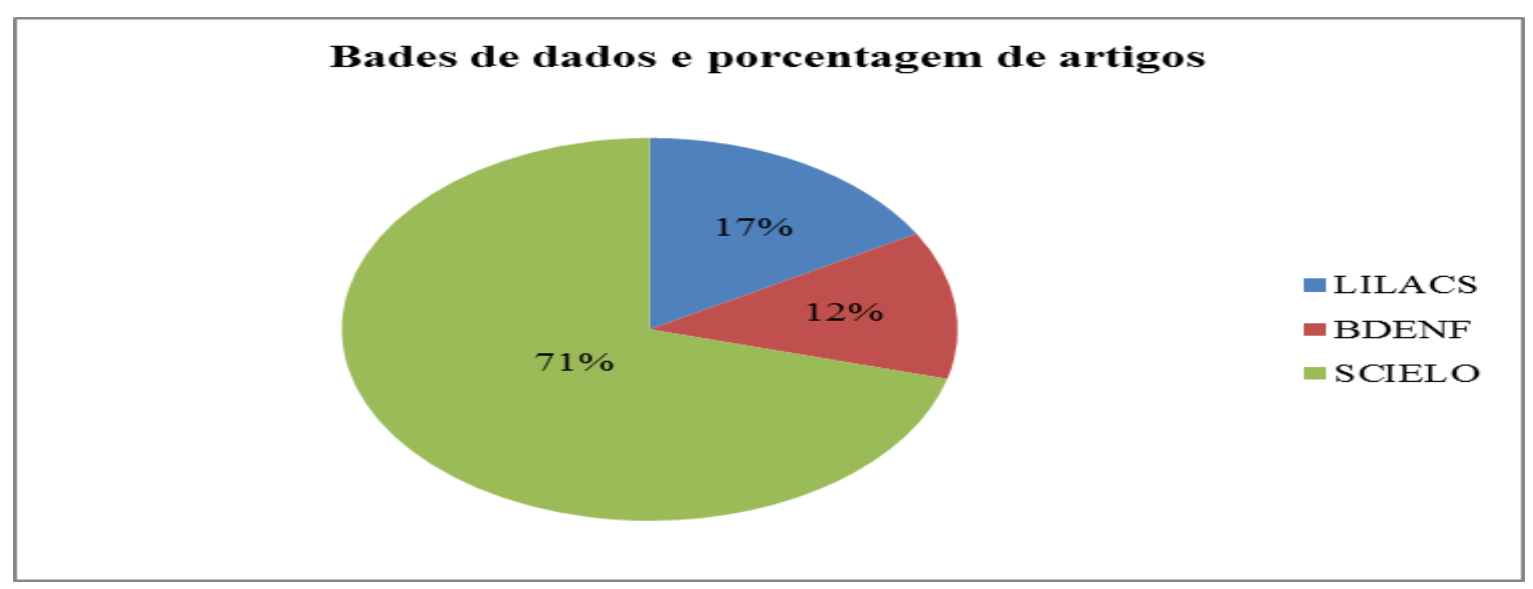

Fonte: Autores (2022).

De acordo com o gráfico ilustrado acima identifica-se as bases de dados e a porcentagem dos artigo publicados em cada uma. Nota - se que na Literatura Latino-Americana e do Caribe em Ciências da Saúde (LILACS) ocorreu (17\%) das publicações, Base de Dados de Enfermagem (BDENF), (12\%) e - Scientific Electronic Library Online (SCIELO) (71\%). Sendo que foram adotados os critérios metodológicos na elaboração do presente estudo.

A Insuficiência Renal Aguda afeta grande parte dos pacientes com problemas renais internados em UTI, é caracterizada pela rápida queda da capacidade dos rins em retirar e filtrar impurezas do organismo, o que leva a distúrbios hídricos, eletrólitos, indicadores ácido-base, responsáveis por elevadas taxas de morbimortalidade. Cerca de $5 \%$ destes pacientes necessitam de tratamento dialítico e, para mantê-los metabolicamente estáveis, a hemodiálise conhecida como terapia de substituição da função renal é o tratamento mais utilizado quando há comprometimento desta função, observando-se bons resultados no tratamento especialmente quanto à assistência de enfermagem (Silva et al., 2017). 
A LRA constitui-se quando os rins (órgãos pares responsáveis pela homeostase do organismo) são impossibilitados por algum advento, extrair os produtos de deterioração metabólicos do organismo ou de realizar seu papel regulador. As substâncias normalmente extraídas na urina concentram-se nos líquidos corporais em decorrência da depleção da excreção renal, afetando as funções endócrinas e metabólicas. Dessa forma, os rins exercem funções fundamentais e indispensáveis na conservação do volume de líquido corporal e na constituição eletrolítica adequada no organismo humano para desenvolver bom desempenho de suas funções. Contudo, constantemente esse sistema apresenta desequilíbrio no funcionamento ao lidar com pacientes críticos, especialmente quando apresenta distúrbio renal, inclusive decorrente da LRA, levando a um aumento acentuado da mortalidade nas UTIs (Nobre et al., 2021).

A definição e classificação da LRA sofreram modificações ao longo dos anos no sentido de promover condições de identificação precoce, com o objetivo de se instituírem intervenções de maior sucesso. A mais recente definição é aquela proposta pelo grupo "Kidney Disease Improving Global Outcomes" (KDIGO), que define a LRA pelo aumento da creatinina sérica em valores maiores ou iguais a $0,3 \mathrm{mg} / \mathrm{dl} \mathrm{em} 48$ horas ou aumento de $1,5 \mathrm{vez}$ da creatinina sérica em relação ao nível basal (conhecido ou pré-estabelecido), ou fluxo urinário menor que $0,5 \mathrm{ml} / \mathrm{kg} / \mathrm{h}$ por 6 horas. Essa definição determina com precisão a variação dos valores de creatinina sérica a ser considerada, mas também mantém o fluxo urinário como marcador de disfunção renal, possibilitando a análise dinâmica de mais do que um marcador para diagnosticar a LRA no paciente crítico. A definição da LRA clínica pelo KDIGO capacitou profissionais da saúde a exercitar a sua identificação precoce beira leito, sendo o enfermeiro o profissional que atua mais proximamente ao paciente crítico e que deve se subsidiar de conhecimento para interpretar, juntamente com toda a equipe, a composição de características clínicas que direcionem para a formulação diagnóstica e de intervenções precoces (Coelho et al. 2017).

A lesão renal aguda tem representatividade significativa na morbimortalidade dos pacientes na Unidade de Terapia Intensiva (UTI) e está associada a piores desfechos até mesmo após a alta hospitalar. Os pacientes críticos são mais suscetíveis a desenvolvê-la principalmente por conta da instabilidade clínica e fatores de riscos prévios, como a idade avançada, sepse, hipovolemia, cirurgias, uso de medicamentos nefrotóxicos, entre outros. Além disso, a LRA está relacionada a diferentes comorbidades que provocam a perda da capacidade de autorregulação de órgãos, como hipertensão e diabetes. A LRA é uma das complicações mais observadas em UTI; contudo, por vezes, é subdiagnosticada e está associada à maior necessidade de uso de drogas vasoativas, ventilação mecânica, sedação, bem como maior tempo de internação e aumento dos custos hospitalares, podendo evoluir para doença renal crônica e até mesmo a morte. Esse cenário exige por parte da equipe de saúde uma programação de assistência segura e de qualidade, capaz de conhecer o perfil clínico e de gravidade desses pacientes. Além disso, indivíduos com esse agravo exigem da equipe mais cuidados quando comparados àqueles sem o agravo (Santana et al. 2021).

Neste sentido, o profissional enfermeiro faz-se presente e atuante diante deste cenário, realizando e fazendo ser executada a SAE com a prescrição de enfermagem, inclusive registro rigoroso do balanço hídrico para quantificar a diurese, já que a mesma faz parte do critério para diagnóstico. Desta forma, sua implantação possibilita ao enfermeiro uma assistência com mais qualidade, eficiência e conferindo maior segurança aos pacientes e profissionais, pois esta ferramenta auxilia na organização do processo de trabalho evidenciando a contribuição da enfermagem na atenção à saúde. As atribuições do enfermeiro perpassam a técnicas ou procedimentos bem realizados e eficientes, já que lançam mão de uma ação cuidadora, integral, holística e contínua, além de uma efetiva comunicação enfermeiro-paciente (Nobre et al., 2021).

O enfermeiro que exerce o papel de cuidado do paciente crítico tem por dever acompanhar, analisar e identificar o desenvolvimento de LRA. A identificação precoce da LRA, ou melhor, a determinação de fatores relacionados ou a definição de características definidoras permitem estabelecer as primeiras diretrizes para a assistência de enfermagem. As ações do enfermeiro de UTI no cuidado a esse paciente devem incluir a monitorização rigorosa do balanço hídrico, o controle de valores 
baixos de monitorização da pressão venosa central, bem como a confirmação de redução do fluxo urinário, pois esses fatores podem indicar depleção de volume decorrente de, por exemplo, jejum prolongado para procedimentos cirúrgicos ou exames diagnósticos em pacientes idosos, vômitos ou diarreias, perdas de grande quantidade de fluídos por drenos e incisões cirúrgicas (Silva et al., 2020).

São inúmeras as incumbências do enfermeiro que presta cuidados ao paciente portador de LRA em HD, este profissional atua diante das intercorrências intradialíticas, prevenindo possíveis complicações como: hipotensão/hipertensão arterial, hipoglicemia/hiperglicemia, desconforto respiratório, taquicardia, saturação, sangramentos, controle das perdas durante a HD, administração de medicamentos prescritos e ainda no tratamento de emergência das disfunções hidroeletrolíticas, avaliando a evolução e a resposta do paciente ao tratamento (Nobre et al., 2021).

Diante disto, a enfermagem trabalha oferecendo suporte físico e emocional, além de atuar cuidando do distúrbio primário que desencadeou a LRA. Quanto aos sinais clínicos e intercorrências apresentados durante a sessão de HD precisa ser atendido imediatamente de forma precisa e adequada para não se obtenha desfecho negativo, como piora do quadro clínico, prolongamento de permanência hospitalar, cronificação da doença ou até mesmo o óbito. Nesta conjuntura o enfermeiro é um profissional habilitado e qualificado que desempenha função fundamental no acompanhamento do paciente em hemodiálise, pois ele é quem assiste diretamente o paciente durante a sessão de hemodiálise e é crucial que o mesmo atenda prontamente as potencias intercorrências. A assistência de enfermagem ao paciente em HD engloba o processo de enfermagem sistematizando, os cuidados de forma humanizada e individualizada mesmo antes do início do tratamento, sempre observando continuamente o aspecto geral e promovendo uma avaliação criteriosa (Nobre et al., 2021).

Assim, ações de triagem de indivíduos com risco de desenvolver LRA devem ser empregadas no âmbito pré-UTI. A institucionalização de protocolos clínicos ajustados à realidade também se configura como saída importante para redução dos casos de LRA negligenciados. O gerenciamento de líquidos, de responsabilidade da equipe de enfermagem e médica, deve ser rigorosamente realizado. A avaliação da resposta do paciente aos diuréticos é outro ponto merecedor de atenção, bem como a não hesitação na realização da TRS precoce (Lopes et al., 2021).

A busca por terapias que minimizem os danos renais na presença de sepse tem sido frequente nas unidades de terapia intensiva. Cabe ao enfermeiro, enquanto membro da equipe multidisciplinar, cuidar dos pacientes nas diferentes situações, de forma integrada e contínua, dentro dos preceitos éticos e bioéticos da profissão, buscando conhecer tratamentos inovadores que promovam melhor assistência de enfermagem aos pacientes (Vasco et al., 2018).

O tratamento da LRA inclui medidas para corrigir a causa da LRA e os desequilíbrios metabólicos que ocorrem como resultado da insuficiência renal. Esses desequilíbrios podem incluir: hipercalemia, uremia, produção de citocinas e deficiências endócrinas. Os objetivos do tratamento também devem focar na preservação da função de todos os órgãos existentes, podendo haver necessidade de incluir as técnicas de substituição da função renal, que podem ser intermitentes ou contínuas ou a diálise peritoneal. Nesse aspecto, o enfermeiro é um elemento crucial na prevenção na LRA e na coordenação de cuidados ao paciente renal, incluindo o doente com LRA. Neste sentido, um doente com LRA, internado numa UCI, exige da equipa de enfermagem intervenções específicas e fundamentais para colmatar as necessidades do paciente.

\section{Conclusão}

Evidenciou-se no estudo, que nas UTIs a equipe de enfermagem que assiste um paciente em cuidados intensivos deve ter acima de tudo comprometimento com a profissão sinalizado pelo cuidado seguro à vida humana, pois mesmo aqueles pacientes assistidos estão predispostos ao desenvolvimento da LRA e agravo do quadro clínico, prognóstico e desfecho. Dessa forma, na equipe multiprofissional o enfermeiro tem assumido um papel protagonista no que se refere à assistência, pois encontra-se diretamente em contato com o paciente. Além disso, tem uma importância fundamental para a identificação 
precoce da LRA. Dentre de suas funções ressalta-se a monitorização dos pacientes que fazem uso de medicamentos nefrotóxicos e medicamentos que reduzem a perfusão renal, uso de contrastes, identificação de patologias que predispõem a LRA, sinais de hipoperfusão e hipotensão. Sobretudo, acumula competências que viabilizam a identificação de sinais e sintomas da LRA, a partir dos resultados das dosagens séricas de uréia e creatinina e realização do balanço hídrico.

Entende-se que a LRA é previsível e pode ser evitável se fatores de risco precoces são identificados precocemente no contexto clínico. Detecção oportuna de LRA não diagnosticada em pacientes hospitalizados também pode levar a uma melhor gestão da doença. Diante desse contexto, a partir dos achados deste estudo é possível concluir que a LRA é uma importante complicação no cenário da UTI sendo relacionada a outras patologias e medicamentos, que podem levar o paciente a desenvolver a disfunção renal.

Considera-se que a enfermagem exerce papel fundamental na identificação da LRA, avaliação, prevenção e tratamento e pode gerar impacto na qualidade da assistência individualizada e assim contribuir com a redução das taxas de mortalidade. Desse modo, torna-se interessante a realização de estudos futuros com a finalidade de ampliar a produção científica a respeito dessa temática tão relevante, sendo de suma importância, no sentido de aprofundar discussões que possam contribuir para a promoção da saúde e na melhoria da qualidade de vida desses pacientes.

\section{Referências}

Amorin, F., de Cássia Altino, R., \& Saranholi, T. L. (2017). Principais causas para o desenvolvimento de lesão renal aguda em Pacientes internados em unidade de terapia intensiva. CEP, $17011,160$.

Aoki, B. B., Fram, D., Taminato, M., Batista, R. E. S., Belasco, A., \& Barbosa, D. A. (2014). Lesão renal aguda após exame contrastado em idosos1. Revista Latino-Americana de Enfermagem, 22, 637-644.

Augusto, C. A., Souza, J. P. D., Dellagnelo, E. H. L., \& Cario, S. A. F. (2013). Pesquisa Qualitativa: rigor metodológico no tratamento da teoria dos custos de transação em artigos apresentados nos congressos da Sober (2007-2011). Revista de Economia e Sociologia Rural, 51(4), 745-764.

Benichel, C. R., \& Meneguin, S. (2018). Fatores associados à lesão renal aguda em pacientes cirúrgicos na unidade de terapia intensiva. Rev Rene, 19 , 1-7.

Cardoso, B. G., Carneiro, T. A., \& da Silva Magro, M. C. (2017). Recuperação de pacientes com lesão renal aguda dialítica e não dialítica. Cogitare Enfermagem, 22(1).

Carneiro, T. A., Hermann, P. R. D. S., Souza, J. M. O. D., \& Magro, M. C. D. S. (2017). Identificação e recuperação da função renal em pacientes não dialíticos no cenário de terapia intensiva. Revista Mineira de Enfermagem, 21.

Coelho, F. U. D. A., Watanabe, M., Fonseca, C. D. D., Padilha, K. G., \& Vattimo, M. D. F. F. (2017). Nursing Activities Score e a lesão renal aguda. Revista Brasileira de Enfermagem, 70, 475-480.

Corrêa, A. S. G., Coutinho, L. S., Jacoud, M. V. L., Carlos, A. R., \& Sória, D. D. A. C. (2020). Manifestações clínicas e intervenções de Enfermagem na lesão renal aguda em terapia intensiva: revisão integrativa. Research, Society and Development, 9(8), e146985396-e146985396.

Dantas, L. A. L., Vieira, A. N., de Oliveira, L. C., da Silva Araújo, M. E., \& de Souza Maximiano, L. C. (2021). Fatores de risco para Lesão Renal Aguda em Unidade de Terapia Intensiva. Research, Society and Development, 10(6), e32210615700-e32210615700.

Ferenhof, H. A., \& Fernandes, R. F. (2016). Desmistificando a revisão de literatura como base para redação científica: método SSF. Revista ACB, 21(3), 550563.

Gomes, T. M., Freire, A., \& Valadares, M. (2016). Pacientes sépticos com lesão renal aguda: realidade da unidade de terapia intensiva. Rev enferm UFPE Online, 10(9), 3190-3196.

Grassi, M. D. F., Dell'Acqua, M. C. Q., Jensen, R., Fontes, C. M. B., \& Guimarães, H. C. Q. C. P. (2017). Diagnósticos, resultados e intervenções de enfermagem em pacientes com lesão renal aguda. Acta Paulista de Enfermagem, 30, 538-545.

Lopes, W. F., Araújo, L. P. D., Prado, P. R. D., \& Amaral, T. L. M. (2021). Incidência, fatores de risco e sobrevida de pacientes em estado crítico com lesão renal aguda. Texto \& Contexto-Enfermagem, 30.

Luft, J., Boes, A. A., Lazzari, D. D., do Nascimento, E. R. P., de Amorim Busana, J., \& Canever, B. P. (2016). Lesão renal aguda em unidade de tratamento intensivo: características clínicas e desfechos. Cogitare Enfermagem, 21(2).

Melo, E. M., Barbosa, A. S., de Araújo Fernandes, L. N., França, N. S., Araújo, S. S., de Abreu, M. A. F., ... \& Araújo, R. M. R. P. Fatores preditivos de lesão renal aguda em pacientes internados em unidade de terapia intensiva. Política Editorial, 2083.

Mendes, K. D. S., Silveira, R. C. D. C. P., \& Galvão, C. M. (2008). Revisão integrativa: método de pesquisa para a incorporação de evidências na saúde e na enfermagem. Texto \& contexto enfermagem, 17(4), 758-764. 
Research, Society and Development, v. 11, n. 3, e25811326257, 2022

(CC BY 4.0) | ISSN 2525-3409 | DOI: http://dx.doi.org/10.33448/rsd-v11i3.26257

Nobre, V. N. N., do Lago, P. N., Vieira, E. C., Simões, M., Silva, F. C. D., de Abreu Junior, R. A., \& Martins, F. R. (2021). Lesão renal aguda: assistência de enfermagem durante a sessão de hemodiálise em Unidade de Terapia Intensiva. Research, Society and Development, 10(8), e12910817108-e12910817108.

Pereira, A. S., Shitsuka, D. M., Parreira, F. J., \& Shitsuka, R. (2018). Metodologia da pesquisa científica.

Pereira, B. J., Badaoui, M., Soeiro, M. D., Gentil, T. M. S., Alvares, V. R. D. C., Scaranello, K. L., \& Laranja, S. M. (2016). Lesão renal aguda no pósoperatório de cirurgias não cardíacas em pacientes com recuperação na unidade de terapia intensiva. Rev Soc Bras Clin Med, 14(4), 190-4.

Pereira, C. A., \& Silva, R. B. D. (2021). Lesão Renal Aguda por Síndrome da Lise Tumoral em Unidade de Terapia Intensiva-Conhecimento do Enfermeiro. Revista de Divulgação Científica Sena Aires, 10(1), 5-12.

Santana, K. Y. D. A., Santos, A. P. A., Magalhães, F. B., Oliveira, J. C., Pinheiro, F. G. D. M. S., \& Santos, E. S. (2021). Prevalência e fatores associados à lesão renal aguda em pacientes nas unidades de terapia intensiva. Revista Brasileira de Enfermagem, 74.

Santos, A. L. P., \& Novais, M. E. (2021). Mapeamento de Intervenções de Enfermagem na Lesão Renal Aguda. New Trends in Qualitative Research, 8, 340352.

Santos, L. L. D., \& Magro, M. C. D. S. (2015). Ventilação mecânica e a lesão renal aguda em pacientes na unidade de terapia intensiva. Acta Paulista de Enfermagem, 28, 146-151.

Silva, G. F., de Souza, A. L. T., Sousa, B. D. O. P., Watanabe, M., da Fonseca, C. D., \& Vattimo, M. D. F. F. (2020). Identificação de lesão renal aguda em unidade de terapia intensiva: parâmetros para avaliação clínica de enfermagem. Research, Society and Development, 9(3), e80932451-e80932451.

Silva, G. G. D. O., Nunes, J. T., Barboza, I. R., Barros, T. R. C. C. D. R., Souza, Â. M. L. D., Davim, R. M. B., \& Martino, M. M. F. D. (2017). Distúrbios renais em unidade de terapia intensiva. Rev. enferm. UFPE Online, 4463-4468.

Silva, J. M. M., de Castro, C. M. C., Castilho, C. P. M., Melo, E. R., Carneiro, G. V., Faria, M. C. S., \& Nascimento, T. R. M. (2021). Manejo da lesão renal aguda. Revista Eletrônica Acervo Saúde, 13(5), e7072-e7072.

Silva, K. B., Lemos, F. A., dos Santos, U. G., \& de Souza Dourado, J. (2021). Assistência de enfermagem ao paciente com lesão renal aguda. Research, Society and Development, 10(11), e222101119589-e222101119589.

Soares, C. B., Hoga, L. A. K., Peduzzi, M., Sangaleti, C., Yonekura, T., \& Silva, D. R. A. D. (2014). Revisão integrativa: conceitos e métodos utilizados na enfermagem. Revista da Escola de Enfermagem da USP, 48(2), 335-345.

Souza, M. T. D., Silva, M. D. D., \& Carvalho, R. D. (2010). Revisão integrativa: o que é e como fazer. Einstein, 8(1), 102-106.

Vasco, C. F., Watanabe, M., Fonseca, C. D. D., \& Vattimo, M. D. F. F. (2018). Lesão renal aguda induzida pela sepse: efeito de proteção renal dos antioxidantes. Revista Brasileira de Enfermagem, 71, 1921-1927. 